\title{
DEL HALLAZGO DE DIRHAMES EMIRALES EN DOMINGO PÉREZ (IZNALLOZ, GRANADA)
}

\author{
Miguel Vega Martín \\ Archivo Diocesano de Málaga \\ SALVAdOR PEÑa MARTín \\ Universidad de Málaga
}

\section{Introducción}

El Museo Arqueológico y Etnológico de Granada (MAEGR, en adelante) posee unos fondos notables de monedas medievales con inscripciones árabes, tanto por el número de piezas (más de setecientas), como por la singularidad de algunas de ellas y la representatividad del conjunto ${ }^{1}$. En estricto, no puede afirmarse con plena seguridad que la totalidad del conjunto constituya una colección de monedas andalusíes, porque, al no constar procedencia de algunos de los ejemplares de monedas acuñadas en Oriente, por los Omeyas de Damasco ${ }^{2}$, o en el Norte de África por diversas dinastías ${ }^{3}$, no hay modo de determinar si todas las monedas o fragmentos de monedas conservados en el MAEGR proceden de la Península Ibérica. Pero esto tal vez sea «rizar el rizo». Si bien es cierto que alguno de los ejemplares conservados

\footnotetext{
${ }^{1}$ El cuidado dispensado por el MAEGR a la numismática andalusí se debe al impulso inicial de Joaquina Eguaras Ibáñez, que fue directora de la institución desde 1930 a 1967; sobre su labor puede consultarse la nota necrológica de Fórneas: «Joaquina Eguaras Ibáñez» (1980-81). Posteriormente, hay que destacar la dedicación de Ángela Mendoza Eguaras, de parte de cuya labor damos cuenta en el texto de este estudio. El actual director de MAEGR, Eduardo Fresneda Padilla, ha retomado la línea de investigación numismática, dentro de la que se inscribe nuestra labor de catalogación de monedas árabes. A él y a quienes trabajan con él, en especial a Inmaculada de la Torre, les quedamos muy agradecidos por la acogida, atención y ayuda que nos han dispensado. Por otra parte, también nos ha aprovechado para este estudio nuestra consulta de los fondos numismáticos andalusíes del Museo de Santa Cruz de Toledo.

2 Por ejemplo, la pieza registrada con la referencia E15501, un dirham acuñado, en el año 86/705, en Wāsit (Iraq), principal ceca de los Omeyas orientales. Sobre estos primitivos dirhames orientales pueden consultarse: Codera y Zaidín, Tratado de numismática arábigo-española (1879), 61, n.; «Monedas árabes orientales encontradas en Aragón» (1913); Medina Gómez, Monedas hispano-musulmanas (1992), 78 y ss., y Cano Avila, «Algunos dirhemes hallados cerca de Alcaudete (Jaén)» (1989).

${ }_{3}$ Por ejemplo, la pieza E15537, un dirham acuñado por los almohades en Bujía.

Al-Qanțara XXIII, 1 (2002) 155-192
} 
en el MAEGR puede provenir de hallazgos extrapeninsulares, sí sabemos que todas las piezas representadas - que no los ejemplares concretos- fueron acuñadas o atesoradas, o tuvieron circulación en al-Ándalus, o conjuntamente en al-Ándalus y el Magreb, cuando el Norte de África y la Península constituyeron un mismo ámbito numismático. Esto ocurrió no sólo con los almohades, de quienes sabemos que, por decirlo con las palabras de Hassar-Benslimane ${ }^{4}$, consiguieron establecer «en las dos riberas del extremo occidental del Mediterráneo una misma entidad institucional, un gran conjunto supranacional (si este término puede emplearse aquí)». Sino también antes y después. Y no sólo porque, por ejemplo, los califas omeyas de Córdoba acuñasen moneda en Marruecos ${ }^{5}$, sino porque, a efectos de atesoramiento, circulación e influencia de modelos numismáticos, fueron muchos los momentos en que la unidad ibero-magrebí resulta difícilmente extricable.

Pero precisamente el fondo de monedas árabes del MAEGR destaca por incluir, junto con un alto número de piezas de procedencia desconocida, varios conjuntos de monedas ocultados en su momento, y los datos de su localización y hallazgo, aunque incompletos, ofrecen información histórica de la que en buena medida carecen las piezas sueltas para las que no consta procedencia.

En el MAEGR están, así, depositados: 1) el tesorillo de Píñar, compuesto por un dirham califal omeya, una decena de fracciones de dinar del período de Taifas y cinco soberbios dinares almorávides, que constituyen un hallazgo - o lo que queda de éste- que fue convenientemente descrito en su momento por Mendoza Eguaras 6 ; 2) un pequeño grupo compuesto por cuatro dirhames nazaríes hallados en Montefrío ${ }^{7}$; 3) un conjunto de dieciséis piezas de cobre, los llamados tradicionalmente feluses (es decir, fulūs), con circulación en al-Ándalus durante el período de los Gobernadores y del emirato omeya de

4 «Las relaciones entre el arte meriní y nașrí» (1995), 173.

5 En el propio MAEGR se conservan varios dirhames acuñados por Hišām II en Fez (E15127, E15465, E15468 y E15472). Sobre estas acuñaciones califales en el Magreb, puede verse el trabajo de Sáenz-Díez, Las acuñaciones del Califato de Córdoba en el Norte de África (1984).

6 «Tesorillo de monedas musulmanas de Pínar (Granada)» (1976).

7 Por ejemplo, la pieza E15588; de éstas sólo consta que proceden de Montefrío, sin otros datos acerca del lugar exacto o el momento del hallazgo; si se trataba de un ocultamiento o de piezas localizadas en un espacio relativamente amplio... 
Córdoba, encontrado en Atarfe (Granada) 8 ; 4) varias decenas de fragmentos de dirham, procedentes de Domingo Pérez (Iznalloz, Granada), con circulación en al-Ándalus en la época del califato omeya de Córdoba ${ }^{9}$; y 5) este hallazgo, también de Domingo Pérez, del que pasamos a ocuparnos.

Se trata de un conjunto relativamente voluminoso de piezas de los siglos II-III de la hégira/VIII-IX de Cristo, encontradas, a comienzos de la última década de los ochenta, en Domingo Pérez, del municipio de Iznalloz, en el norte de la provincia de Granada. La existencia de este hallazgo era ya conocida en medios especializados. La misma Mendoza Eguaras, a la sazón Directora del MAEGR, dio, poco después del hallazgo, una pequeña noticia acerca de la primera fracción de éste que ingresó en el MAEGR ${ }^{10}$, que transcribimos en su totalidad:

Apareció este Tesoro al realizar labores de campo en la finca de D. Rafael Utrilla Orihuela y fueron recogidas por éste y por D. Juan Valenzuela García, Don Antonio Leyva Martínez, D. Norberto Labraz López y D. Pedro Sánchez García en la primavera de 1982. Ingresaron en el Museo en enero de 1983.

Fue adquirido por el Estado, mediante expediente de indemnización aprobado el 20 de diciembre de 1982.

Consta de 300 dirhemes de los Emires Independientes, 'Abd al-Raḥmān I a ${ }^{\mathrm{c} A b d}$ Allāh. Pesa 637,93 gramos y es legible la fecha de gran número de ellas, por su buen estado de conservación. Actualmente está en estudio para su publicación.

Con posterioridad a la aparición de esta breve nota se produjo, primero, la adquisición por el MAEGR de un nuevo lote de monedas, pertenecientes al mismo hallazgo ${ }^{11}, \mathrm{y}$, después, la lamentable muerte de la investigadora, razón seguramente de que el anunciado estudio no apareciera. ción.

${ }^{8}$ Por ejemplo, las piezas E15676 o E15671; de éstas tampoco consta más informa-

9 Por ejemplo, las piezas E15719 o E15709; de nuevo, sin más datos sobre su hallazgo y localización.

10 «Tesoro de monedas de plata musulmanas de Domingo Pérez (Granada)» (1983).

11 Los primeros 300 dirhames ingresaron en el MAEGR por un expediente de amortización aprobado el 20-12-1982; y los 66 que componían el segundo lote le fueron adquiridos, casi cuatro años más tarde, a D. ${ }^{a}$ Francisca Rosillo García por resolución de la Dirección General de Bellas Artes (Madrid, 5-3-1986). Obsérvese que debe de haber un pequeño error en el traslado de estas cifras a las noticias, dadas en su momento, sobre el conjunto, ya que nosotros hemos tenido acceso a un total de 368 piezas. 
Así las cosas, quienes firmamos estas páginas, al comenzar la catalogación del fondo monetario árabe del MAEGR, decidimos hacer público el hallazgo, que seguía inédito. Una parte del trabajo de descripción estaba hecha, bien por la propia Mendoza Eguaras, bien por algunos investigadores dirigidos por ella. Las monedas nos las encontramos clasificadas por años, tarea que estaba muy avanzada en lo que hace a las piezas que no presentaban problemas de legibilidad (por dificultades epigráficas o por el deterioro de algunos ejemplares); además, de la mayoría de las piezas datadas se daban referencias con arreglo a los dos corpora principales para el período del Emirato: el de Vives y Escudero ${ }^{12}$ y el de Miles ${ }^{13}$.

Nuestra labor ha consistido, entonces, en revisar los datos que el MAEGR puso a nuestra disposición junto con las monedas: peso, módulo, posición de cuños y año de acuñación, y, a partir de ahí, elaborar una ficha completa para cada ejemplar en la que se recogían esos datos (que a veces hubo que corregir), junto con la datación de las monedas que presentaban problemas de lectura, la descripción pormenorizada de sus gráfilas y adornos, la comprobación de las leyendas e inscripciones y cuantos otros datos pudieran ser de interés para la descripción y catalogación del hallazgo, tales como desperfectos o particularidades de peso (por ejemplo, la adición de una grapa).

El resultado ha sido la datación de la gran mayoría de las piezas, incluso aquellas que presentaban el año borrado, por medio del estudio de los adornos y rasgos epigráficos; la localización y atribución de las monedas no andalusíes (tres idrīsíes y una 'abbāsí), cuyo origen extrapeninsular había pasado desapercibido, y la confrontación, lo más afinada posible, con los ejemplares descritos en los corpora antes mencionados, para determinar variantes de las piezas descritas. $Y$ he aquí los resultados del trabajo.

12 Monedas de las dinastías arábigo-españolas (1893).

13 The Coinage of the Umayyads of Spain (1950). 


\section{Una primera aproximación al conjunto de piezas}

\subsection{En torno al hallazgo}

Los hechos concretos del cuándo, dónde, quién y cómo del hallazgo han quedado expuestos en la nota de Mendoza Eguaras antes transcrita. A ellos debemos añadir una observación importante: que es probable que el hallazgo nos haya llegado incompleto. Como hemos visto antes, el MAEGR adquirió el conjunto en dos momentos distintos, lo cual deja lugar a la duda de si hubo algunas otras piezas halladas, pero de las que no tenemos noticia. Esta sospecha parece confirmarla el escaso número de fragmentos contenidos en el hallazgo de Domingo Pérez frente a lo que es usual en otros. En nuestro caso, de un total de 368 piezas, sólo 13 son fragmentos ${ }^{14}$, proporción muy inferior a la de otros hallazgos del Emirato. Así, por ejemplo, en el de Iznájar (Granada), frente a 641 monedas completas, se recogieron 402 «fragmentos o añadidos» 15; y el de Arraiolos, en el Alentejo portugués, consta de un total de 150 piezas, de las cuales 10 son fragmentos ${ }^{16}$, con una proporción baja, pero aún notablemente superior de la de Domingo Pérez.

Estamos, en suma, ante un conjunto de 364 piezas emirales omeyas, 13 de ellas fragmentarias, y cuatro monedas más, acuñadas fuera de la Península Ibérica: tres en Marruecos, por la dinastía idrīsí, y una sola, en Egipto, por los 'abbāsíes de Bagdad, que - recordémosloeran todavía los únicos titulares de la jefatura califal.

Una buena parte de las piezas, sobre todo las andalusíes, nos ha llegado en un aceptable estado de conservación. Se trata, en general, de monedas que no debieron de circular en exceso; de modo que la mayoría de los desperfectos observables se debe a alguna de las razones siguientes: a) desgaste de los cuños empleados en la ceca o mala acuñación de la pieza; b) recortes $u$ otras agresiones sobre las monedas fuera de la ceca, y c) la presencia, en una proporción bastante elevada, de concreciones de óxido producidas con el paso del tiempo, que, antes de su eliminación, dificultaban la lectura de algunas piezas.

${ }^{14}$ Se trata de los n. ${ }^{\text {os }} 53,134,148,157,168,175,208,212,360,361,362,363$ у 364 de nuestro catálogo.

15 Canto García y Marsal Moyano, «Hallazgo de moneda emiral de Iznájar (Granada)» (1988), 428.

16 Marinho, «Uma prática singular em moedas do Emirado do Ândalus» (1983). 
Hay que reseñar, por último, que nada sabemos del recipiente donde pudieron encontrarse las monedas. Y tampoco si, junto con éstas y los fragmentos, aparecieron algunos otros objetos, lo cual no es extraño en hallazgos andalusíes ${ }^{17}$.

\subsection{Generalidades históricas}

Hemos dicho que la casi totalidad de las monedas del hallazgo fue acuñada por el emirato omeya de Córdoba, el primer Estado independiente islámico que se constituyó en la Península Ibérica, como uno de los primeros pasos hacia la desmembración del califato 'abbāsí de Bagdad.

Los dos momentos clave en la constitución de ese Estado como entidad autónoma quedan bien representados por las piezas de Domingo Pérez: en primer lugar, a causa de la presencia de monedas acuñadas por ${ }^{\mathrm{c}} \mathrm{Abd}$ al-Raḥmān I, desde años muy remotos, ya que el dirham más antiguo de nuestro catálogo data del año 150/767-8. Y, en segundo, por la abundancia de monedas acuñadas por ${ }^{\mathrm{c}} \mathrm{Abd}$ al-Raḥmān II, a cuya labor al frente del emirato cordobés debemos prestar alguna atención.

Conocidos de los historiadores son los diversos aspectos de la realidad política, económica y cultural que hacen del mandato de ${ }^{\mathrm{c}} \mathrm{Abd}$ al-Raḥmān II un período fundamental en la historia de al-Ándalus, que a nosotros nos interesa particularmente porque a ese emir podemos atribuirle la acuñación de más de la mitad de las monedas aquí descritas ${ }^{18}$. Con él se pacificaron en parte los enfrentamientos internos, a él se debe la labor de organización burocrática del Estado en sus más finos detalles, él impulsó la producción de moneda para afianzar el comercio y él inició lo que puede llamarse «orientalización de la España musulmana», por una serie de medidas que, en

17 Sobre los diversos aspectos de los hallazgos monetarios andalusíes, en general, véase Canto e Ibrahim, «Evolución de la moneda andalusí» (1997), 75-9.

18 Probablemente podemos atribuirle a ${ }^{\mathrm{C}} \mathrm{Abd}$ al-Raḥmān II las monedas acuñadas entre los años 208 y $238 \mathrm{~h}$., con cierto margen de duda acerca de los dos años mencionados, ya que no tenemos seguridad de si durante los mismos hubo acuñaciones del emir que lo precedió y el que lo sucedió. Miles sí que atribuye a ${ }^{\mathrm{C}} \mathrm{Abd}$ al-Raḥmān II todas las acuñaciones de esos dos años. Si así es, de él serían las monedas $n .{ }^{05}$ 25-295 de nuestro catálogo. 
suma, consistían en adoptar modelos propios de los 'abbāsíes. Esto, dotando al Emirato de una organización burocrática sólida, monopolizando sus servicios, instaurando una rígida jerarquía entre quienes lo servían en las tareas de gobierno y estableciendo un protocolo para la vida cortesana. La imagen, pues, que de este emir nos transmite la historiografia ${ }^{19}$ es la de un eficiente estadista que impulsó -0 al menos lo intentó- el establecimiento de una sólida estructura estatal.

La imitación de modelos orientales, o el deseo de emular a los 'abbāsíes, dejó huellas visibles en las monedas. Nos referimos al cambio de orden estético que se produjo, sobre todo, en las acuñaciones de los años 229/843-4 y los dos siguientes; reforma estética que fue acompañada de una manifiesta mejora técnica en la producción de piezas. Si bien es cierto que se conservan monedas con esos mismos 0 parecidos rasgos, acuñadas varios años después, en $241 / 855-6^{20}$, ya concluido el mandato de ${ }^{\mathrm{C}} \mathrm{Abd}$ al-Rahmān II, sin que hasta el momento, y que sepamos, se hayan aún extraído consecuencias de la pervivencia, al menos en algunas piezas, de un modelo tan característico, junto a otras en las cuales se aprecia un retorno al descuido formal de los dirhames anteriores al $229 \mathrm{~h}$.

Sea como sea, el hecho es que, durante el período indicado se produjeron monedas de gran belleza y calidad de acuñación, y que, por su diseño y epigrafía, recuerdan claramente los rasgos de los dirhames orientales omeyas que habían circulado por al-Ándalus en el período de los Gobernadores. Estas transformaciones orientalizantes en lo estético coinciden con la presencia sintomática de Ziryāb, el famoso músico oriental que tuvo a su servicio ${ }^{c} \mathrm{Abd}$ al-Raḥmān II y que tanto influyó en los modos y formas de la vida cortesana cordobesa ${ }^{21}$.

Por otro lado, hay que considerar que las monedas más recientes del hallazgo están fechadas en el año 242/856-7, que - es de suponer - será la fecha del ocultamiento. Éste se produjo en terrenos de lo

19 Lévi-Provençal, España musulmana hasta la caída del Califato de Córdoba (711-1031 de J.C.) (1950), 163 y ss.; Arié, España musulmana (siglos VII-XV) (1984), 60 y 107 , especialmente.

${ }^{20}$ Nos referimos a un dirham del cual se conserva un ejemplar en el Museo de Santa Cruz de Toledo (Ref. 8470).

21 Todo esto puede ampliarse en Vega Martín, M., y Peña Martín, S., «La mejora epigráfica del $229 \mathrm{~h}$.: sentido y forma en las leyendas del dirham emiralı (2001). Y recuérdese que, para el papel de Ziryāb y, en general, la orientalización del emirato omeya, contamos con el relato ya clásico de Lévi-Provençal, La civilización árabe en España (1955), 65 y ss. 
que, con arreglo a la división geográfica de la época, se conoce como la cora de Elvira, que aproximadamente coincide con la actual provincia de Granada; zona que durante el Emirato se caracterizó por lo heterogéneo de su población, compuesta por grupos étnico-religiosos que mantenían conciencia de tales frente a un Estado aún no bien constituido ${ }^{22}$.

Precisando un poco más, los territorios que ahora forman parte del término de Iznalloz o de sus inmediaciones constituían la comarca que los andalusíes llamaban al-Barāi ${ }^{-1}{ }^{23}$, en la cual podemos situar, pocas décadas después de la fecha indicada para el ocultamiento de nuestro hallazgo, manifestaciones graves de los conflictos internos que convulsionaron al Emirato, hechos en los que desempeñó algún papel la fortaleza de Montejícar ${ }^{24}$, también en las inmediaciones.

\subsection{Generalidades numismáticas}

Las obras clásicas españolas de numismática andalusí prestaron, desde el principio, a la acuñación y circulación monetarias durante el Emirato tanta atención como a los períodos subsiguientes ${ }^{25}$, y muy pronto - a finales del siglo XIX - se contó con un corpus general exhaustivo, el de Vives y Escudero ${ }^{26}$. Sin embargo, a diferencia de lo que ha ocurrido con la amonedación de otros períodos ${ }^{27}$, la del Emirato no ha dado lugar a ninguna gran monografía, salvo que consideremos como tal el importantísimo corpus de Miles, que presenta la particularidad de extenderse también a la amonedación califal. De cualquier modo, este último trabajo cuenta con medio siglo de existencia, y muestra ya - como no podía ser de otra forma - ciertas ca-

\footnotetext{
${ }^{22} \mathrm{Al}$ respecto, puede verse Lévi-Provençal, España musulmana (1950), 219 y ss.

23 Jiménez Mata, La Granada islámica (1990), 156 y ss. (s.v.); y véanse también las entradas correspondientes a otros topónimos de la comarca o sus inmediaciones: Andar, Arenales, Torrecardela, Colomera, Deifontes, Escusar, Faucena, Fraje, Íllora, Iznalloz, Moclín, Montejícar, Oveilar, Píñar, Tocón y Torrecillas (s.v.).

${ }^{24}$ Lévi-Provençal, España musulmana (1950), 220 y 222.

${ }^{25}$ Cfr. Codera y Zaidín, Tratado de numismática arábigo-española (1879), 57-74.

${ }^{26}$ Monedas de las dinastías (1893), VIII-XIV y 3-35.

27 Pensamos en trabajos tan destacados como los de Prieto Vives (1915), «La reforma numismática de los almohades», o Frochoso Sánchez, Las monedas califales de ceca al-Ándalus y Madinat al-Zahrä' (1996).
} 
rencias. El catálogo que presentamos más abajo da prueba de algunas de ellas.

Pues, efectivamente, los hallazgos emirales descritos en fuentes secundarias durante las últimas décadas incluyen ejemplares que hay que clasificar como variantes de las piezas registradas tanto por Vives y Escudero como por Miles. Y en este punto el hallazgo de Domingo Pérez resulta en extremo ilustrativo, como puede comprobarse a simple vista en la lista de monedas que presentamos.

Además de eso, la historia de la amonedación del Emirato sigue planteando numerosos interrogantes. Limitémonos a uno sólo, de gran calado, eso sí, como indicativo de esto que decimos: en qué consistió exactamente el papel de ${ }^{\mathrm{c}} \mathrm{Abd}$ al-Raḥmān II en la historia monetaria andalusí, más allá de la abundancia de sus acuñaciones, hecho bien reflejado por los investigadores ${ }^{28}$. Pues las fuentes históricas generales le conceden uno muy alto, sin que sepamos a ciencia cierta cómo encajar estas afirmaciones en la historia concreta de las monedas. Recordemos lo que al respecto afirmaba Lévi-Provençal, en el contexto de sus explicaciones sobre la gran labor administrativa que correspondió a ese emir ${ }^{29}$ :

\footnotetext{
El poder real se traduce en Córdoba, como en Bagdad, por la institución de los monopolios del Estado: acuñación de moneda y mantenimiento de los talleres en que son tejidas las preciosas telas que llevan el nombre del soberano reinante. Los historiadores de al-Andalus atribuyen esta doble iniciativa a 'Abd al-Rahman II. Anteriormente a él - dicen-, las monedas acuñadas dentro de España eran muy raras, y casi únicamente dirhemes de plata y óbolos ( fals) de bronce; las piezas que circulaban en el país, sin hablar de algunos raros dinares de oro, eran generalmente africanas $u$ orientales, y su número reducido perjudicaba las transacciones comerciales, muchas de las cuales debían hacerse por simple permuta. [...] 'Abd al-Rahman II quiso poner remedio a los inconvenientes de esta situación multiplicando el número de piezas de plata y de bronce que circulaban, $\mathrm{y}$ con este objeto creó en Córdoba una «ceca» o casa de la moneda (dar al-sikka), cuya dirección confió al especialista Harith ben Abi-1-Shibl.
}

Posteriormente, otra de los grandes especialistas en historia general de al-Ándalus, Arié ${ }^{30}$, situaba entre los años 822 y 831 d.C. la

${ }^{28}$ Por ejemplo, por Ariza Armada, «La colección de dirhames del Emirato omeya andalusí conservada en la Real Academia de la Historia» (1997).

${ }_{29}$ España musulmana (1950), 164-5.

30 España musulmana (siglos VIII-XV) (1984), 605. 
«fundación en Córdoba de la primera ceca oficial» y las «primeras acuñaciones en plata».

Aun admitiendo que pueda haber algunas imprecisiones en las afirmaciones de estos dos investigadores, sigue abierta una serie de interrogantes que, por lo que sabemos, no se han aclarado suficientemente en la investigación numismática especializada. Pues, ¿quiere lo anterior decir que las acuñaciones previas a ${ }^{c} \mathrm{Abd}$ al-Raḥmān II se hacían por algún tipo de concesión a algún notable? ¿O sólo que existían simultáneamente varias cecas emisoras de titularidad estatal? Y, asimismo, ¿hasta qué punto crecieron en lo cuantitativo las acuñaciones debidas a este emir? No lo sabemos, ni nos corresponde aquí otra labor que llamar la atención sobre estos enigmas.

Enigmas que, escuetamente, se condensan en las visiones contrapuestas que del asunto han ofrecido, a lo largo del siglo XX, las principales fuentes secundarias numismáticas. Pues, por un lado, Prieto Vives afirmaba tajantemente en la década de los veinte del pasado siglo ${ }^{31}$, y refiriéndose al hecho bien conocido de que en las monedas emirales se declara que se han acuñando «en al-Ándalus»:

Muchos traducen Alandalus por Córdoba, siendo su significación España; las monedas no se acuñaron en Córdoba hasta el reinado de Abderrahmán II, que duró de 206 a 238 [...].

Mientras que, por el contrario, Canto García, seguramente el máximo especialista actual en amonedación omeya andalusí, escribió hace poco y con parecida rotundidad ${ }^{32}$ :

La tradición omeya de la que 'Abd al-Rahmān I estaba plenamente imbuido, le conducía a una organización de la producción de moneda centralizada; así, la dār al-sikka situada en Córdoba será la única en funcionamiento para todos los emires omeyas $[\ldots]$.

En suma, lo que está por desentrañarse de una vez por todas es si, al menos antes de ${ }^{c} \mathrm{Abd}$ al-Raḥmān II, hubo una sola ceca, como defiende Canto García, o si, por el contrario, la denominación genérica

31 Y remitiendo a Al-Bayān al-Mugrib de Ibn 'Idārī, edición de Fagnan, II, 148; en su clásico Los Reyes de Taifas: Estudio histórico-numismático de los musulmanes españoles en el siglo $\mathrm{V}$ de la hégira (XI de J.C.), 96, n. 1.

32 En su excelente visión de conjunto sobre la moneda en al-Ándalus hasta el período de Taifas, «La moneda andalusí: ¿un modelo de moneda distinto?» (1999), 78. 
de al-Ándalus responde a diversas cecas distribuidas por la Península, como parece desprenderse de la visión de los hechos de Prieto Vives, Lévi-Provençal y Arié. Y habrá que recordar que a esto último, a la presencia de más de una ceca emisora, parece apuntar el que, todavía en época almorávide, el almotacén sevillano Ibn 'Abdūn escribiese (en versión de García Gómez) ${ }^{33}$ :

En el país no debe correr otra moneda que la de la ceca oficial, porque la variedad de cecas da motivo para que se desvalorice la moneda, se multipliquen los cambios y las circunstancias económicas se alteren y se salgan del curso ordinario.

Decimos que no nos corresponde tratar de resolver el problema, pero sí dejar constancia de que los datos del catálogo del hallazgo de Domingo Pérez, como de otros, no permiten, por la continuidad que muestran en las cantidades de ejemplares y por los datos que proporcionan las propias monedas, concretar en nada las reformas sustanciales atribuidas a ${ }^{\mathrm{c}} \mathrm{Abd}$ al-Rahmān II. Sino, como mucho, el aventurar algunas posibles hipótesis de trabajo, como hacemos más abajo.

Todas estas cuestiones y carencias, junto con algunas otras sin duda, siguen dándole la razón a Canto García ${ }^{34}$ cuando, hace ya algunos años, se quejaba del «abandono» de la época emiral por parte de los historiadores de la moneda; y justifica plenamente la satisfacción de Wasserstein ${ }^{35}$ ante la aparición - no muy frecuente - de trabajos donde se describen con minuciosidad corpora de moneda emiral.

\section{Análisis de algunos rasgos del conjunto de piezas}

El examen del catálogo correspondiente al hallazgo de Domingo Pérez nos permite hacer una serie de observaciones, de las que entresacamos aquí las que creemos que deben hacerse explícitas. Por supuesto, los datos del propio catálogo ofrecen la posibilidad de extraer

33 Lévi-Provençal y García Gómez, Sevilla a comienzos del siglo XII: El tratado de Ibn 'Abdūn (1948), 176-7.

34 «El período omeya. El Emirato. La aparición de la tipología califal. 'Abd al-Rahman III: sus sucesores» (1988a), 29.

${ }^{35}$ «Islamic coins and their catalogues: a problem case» (1999), especialmente 230. 
otras conclusiones, sobre todo a partir de su comparación con los de otras descripciones de hallazgos o conjuntos emirales ${ }^{36}$.

\subsection{Años representados}

En total - ya lo hemos dicho-, estamos ante 368 piezas de plata o dirhames, completos, recortados o fragmentados, de las cuales hemos dejado siete sin datar. Todas las demás o bien ofrecen escasos problemas de lectura en cuanto al año de su acuñación o bien presentan rasgos de decoración o epigrafía que nos han dado la pista sobre los años en que se produjeron. De manera que, excluyendo los dirhames acuñados fuera de la Península Ibérica, tenemos 357 piezas emitidas a lo largo de un arco temporal que va desde el año 150/767-8 al 242/856-7; esto es, casi una centuria, de la que faltan los años siguientes: $151-152,155-176,178-190,192-193,195-196,198,202$, $205,207,210-211$ y $215-216 \mathrm{~h}$.

Respecto a los años sí presentes en el hallazgo, la proporción en piezas es muy heterogénea. En las fechas más remotas son frecuentes los años representados por una sola (por ejemplo, 150, 153 y $191 \mathrm{~h}$.), mientras que, a medida que nos acercamos al año $242 \mathrm{~h}$., suele aumentar el número de piezas por año; así, si del $201 \mathrm{~h}$. son 4 las piezas registradas, en el $220 \mathrm{~h}$. pasamos a 11 . Los años más copiosos son el $237 \mathrm{~h}$., del que hay 37 piezas, y, sobre todos, el $238 \mathrm{~h}$., del que hemos contado 41. Aunque tal vez pueda afirmar que, en conjunto, el año más rico e interesante desde nuestra perspectiva es el $237 \mathrm{~h}$., por el número de piezas que presentan variantes de adorno respecto a lo registrado en el corpus de Miles ${ }^{37}$.

\subsection{Emires representados}

Si consideramos que ${ }^{c} A b d$ al-Raḥmān III, el primer califa cordobés, fue asimismo el último gobernante del Emirato, tenemos enton-

\footnotetext{
${ }^{36}$ Labor de descripción que sabemos que se está realizando, en buena parte gracias a la labor e impulso de Canto García, que ha dirigido o dirige en la actualidad estudios descriptivos sobre monedas emirales omeyas (comunicación personal).

37 The Coinage of the Umayyads of Spain (1950).
} 
ces que los titulares de éste fueron ocho emires. Los cinco primeros, 'Abd al-Raḥmān I, Hišām I, al-Ḥakam I, 'Abd al-Raḥmān II y Muhammad I, están representados, por sus acuñaciones, en nuestro hallazgo. Como era de esperar, destacan los dos últimos. ${ }^{c} A b d$ al-Raḥmān II, por lo largo de su reinado y lo copioso de sus emisiones monetarias, y Muhammad I, porque era el gobernante cuando se produjo el ocultamiento. Del total de años durante los que gobernó 'Abd al-Raḥmān II, desde el 206/821-2 al 238/852-3, y teniendo en cuenta que éstos son los dos años límite entre su mandato y los de su antecesor y su sucesor, en el hallazgo de Domingo Pérez hay piezas de todos, excepto 207, 210, 211, 215 y $216 \mathrm{~h}$. Y, contabilizando sólo el período de 208/823 a 237/851-2, lo que elimina las dudas de atribución, son, como mínimo, 229 las piezas que corresponden a este emir (de un total de 368 -recordémoslo-). Así pues, el de Domingo Pérez es un hallazgo notable para nuestro conocimiento de la numismática de ${ }^{c} \mathrm{Abd}$ al-Raḥmān II. Piénsese que en uno de los hallazgos emirales (al parecer, completo) más copiosos ${ }^{38}$, el de Iznájar (Granada), compuesto de más de un millar de piezas (monedas y fragmentos), se ha registrado un total de 282 dirhames acuñados en ese mismo arco de años.

\subsection{Inscripciones}

De entre todas las monedas que se acuñaron en al-Ándalus entre los siglos VIII y XV d.C., los dirhames del Emirato son los que presentan una mayor homogeneidad formal y de contenido textual. Ello se debe a que, dentro del diseño o modelo instaurado por el califato omeya de Damasco en torno al año $77 / 697{ }^{39}$, estas monedas repiten siempre las mismas leyendas ${ }^{40}$, sin más variación que la del año de

${ }^{38}$ Descrito por Canto García y Marsal Moyano, «Hallazgo de moneda emiral de Iznájar (Granada)» (1988).

39 Sobre la reforma numismática de 'Abd al-Malik pueden verse, entre otros muchos trabajos, los de Walker, A Catalogue of the Arab-Byzantine and Post-reform Umaiyad Coins (1956), LV y ss.; Grabar (1973), 101 y ss.; Bates (1982), 14 y ss.; Broome (1985), 10 y ss. Canto García e Ibrahim (1997), 21-2, y Vega Martín, Peña Martín y Feria García, El mensaje de las monedas almohades (en prensa), Capítulo VII.

40 Sobre los textos inscritos en las monedas emirales puede consultarse cualquiera de los trabajos generales que citamos aquí, o bien, para mayor detalle, el nuestro, ya mencio- 
emisión y, en algunos casos, la presencia en el área central de algún nombre propio correspondiente a algún personaje importante en la Corte, y cuyo papel en el proceso de emisión monetaria no se conoce demasiado bien; ya que los emires andalusíes nunca llegaron a grabar sus nombres y títulos en las monedas, a diferencia de lo que hicieron ya los califas cordobeses.

\subsection{Metrología}

Un rasgo bastante común en los hallazgos de dirhames del Emirato es que incluyan un buen número de monedas que han sufrido distintos tipos de agresión que alteran su peso y dimensiones. Es lo que ocurre, por ejemplo, con los hallazgos de Arraiolos ${ }^{41}$ e Iznájar ${ }^{42}$, 0 incluso alguno de menor cuantía, como el de Martos ${ }^{43}$; aunque no falta algún ocultamiento cuyas piezas presentan un alto grado de integridad, como el del Cerro de la Fuensanta ${ }^{44}$.

Estas agresiones adoptan diversas formas, debidas a su vez a la función que tuviesen. De entrada, parece que es necesario dejar a un lado las monedas con perforaciones que las hicieran aptas para engarzarse con algún hilo o cordel, y se utilizasen así como adornos (o tal vez como talismanes, o tal vez como medio de ahorro, o puede que todo a un tiempo). De este tipo de agresión nos deja nuestro hallazgo constancia en un solo caso, y - acaso significativamente- en una de

nado: «La mejora epigráfica del $229 \mathrm{~h} .:$ sentido y forma en las leyendas del dirham emiral» (2001).

${ }^{41}$ Descrito por Marinho en un trabajo muy notable: «Uma prática singular em moedas do Emirado do Ândalus» (1983), donde precisamente se analiza en profundidad este tipo de alteraciones en las monedas.

42 Canto García y Marsal Moyano, «Hallazgo de moneda emiral de Iznájar (Granada)» (1988), donde estos investigadores señalan un número elevado de monedas muy recortadas.

${ }^{43}$ Canto, «Sobre un pequeño hallazgo de moneda emiral en Martos (Jaén)» (1993) donde los módulos de las piezas van desde los 13 a los $29 \mathrm{~mm}$, y sus pesos, desde los 0'67 hasta los 2'64 g.

${ }^{44}$ Gozalbes Cravioto y Ayala Ruiz, «Un tesorillo de monedas del Emirato independiente hallado en el Cerro de la Fuensanta (Antequera-Casabermeja-Colmenar, Málaga» (1995-96), donde las piezas presentan unos pesos muy elevados (2'430 g. la que menos); pero nótese que se trata de un hallazgo de pocas piezas (18, de las cinco primeras décadas del Emirato), lo cual tal vez explique el hecho. 
las pocas monedas no andalusíes: uno de los dirhames idrīíes (n. ${ }^{\circ}$ 367), que presenta dos perforaciones circulares ${ }^{45}$.

Muy distinto es el caso de las monedas con recortes, que en numerosas ocasiones son muy pronunciados, como puede apreciarse por las medidas de módulos que registramos para cada pieza. La lógica parece indicar que tal actuación hay que atribuírsela a particulares (no al Estado), y tendría como objetivo obtener cantidades de plata por procedimientos ilícitos. Las dudas las plantea más bien el resultado obtenido; ya que, según testimonian tanto este hallazgo como otros, la alteración en las dimensiones de la moneda, y, desde luego, también en el peso, tenía que ser tan evidente que sólo cabe pensar en tres posibilidades: a) que las monedas se valorasen por su peso, tal vez en conjuntos; b) que, por el contrario, se atendiera al valor nominal, simbólico, por así decir de cada pieza: un dirham (y sus subsiguientes fracciones, a las que también se darían valores fijos, aun a sabiendas de sus diferencias de peso); c) que los dos sistemas de valoración anteriores tuviesen vigencia, bien simultánea (en distintos ámbitos), bien sucesivamente (por alguna suerte de desmonetización).

Sea como sea, el hecho es que, frente a dirhames emirales de gran módulo y peso, como los n. ${ }^{\text {ss }} 5$ (28'80 mm, 2'6 g.), 72 (29'65 mm, 2'6 g.) o 149 (29'50 mm, 2'6 g.), hay otros muy drásticamente mermados, como los n.os 92 (20'70 mm, 1'3 g.), 144 (20'90 mm, 1'7 g.) o 174 (19'85 mm, 1’3 g.).

Como reacción a esta práctica, sabemos que en ocasiones se procedía a restablecer las monedas recortadas con algún suplemento de peso. Es lo que se hizo con el dirham $n .^{\circ} 211$, que conserva en perfecto estado una grapa metálica encajada por medio de dos perforaciones.

\footnotetext{
45 Las perforaciones de este estilo no son siempre fáciles de distinguir de las realizadas para encajar suplementos de peso. Pero, aun con esa sombra de duda, puede decirse que tenemos constancia de ejemplares de dirhames emirales sometidos a tales prácticas. Un ejemplo podría ser una pieza descrita (y fotografiada) por Canto García, Haâaz Ibrāhīm y Martín Escudero, Monedas andalusies: Catálogo del Gabinete de Antigüeda$\operatorname{des}(2000), \mathrm{n}^{\circ} 825$.
} 


\subsection{Anomalias de diseño o producción}

Junto a un número relativamente alto de monedas con defectos de acuñación (movida o doble) o de grabado (gráfilas en espiral o dobles leyendas en orlas), en nuestro conjunto destacan las piezas donde se observan errores en las leyendas. Y éstos pueden dividirse en dos clases: los que afectan a los numerales y los que alteran los textos sagrados.

En cuanto a las alteraciones de los numerales, también hay que distinguir entre, primero, las que parecen deberse a deseos de abreviar, $y$, en consecuencia, presentan la omisión de la conjunción $w a-$ ' $y$ ' entre los distintos elementos del numeral ${ }^{46}$. Y, segundo, aquellas que podemos considerar errores sin más, derivados seguramente de mal conocimiento de las reglas gramaticales del árabe clásico ${ }^{47}$. Ocurre, así, con cierta frecuencia, que la unidad del numeral no establece la concordancia de género debida con la palabra sana, 'año'. En casos así es probable que hubiese influencia del árabe dialectal andalusí, donde la distinción de género se había perdido en los numerales ${ }^{48}$.

Tal vez ofrezcan más interés los ejemplares en que la palabra afectada pertenece a algunos de los textos islámicos que se inscribían en las monedas. Llaman, sobre todo, la atención los casos en que la palabra sagrada Alläh 'Dios' falta por completo en el grabado correspondiente a la orla del anverso (n. ${ }^{\circ} 323$ ); o bien ha sufrido algún tipo de alteración cuyo resultado es que falte de la segunda línea de la inscripción central del anverso ( . $^{\circ}$ 276); o bien haya desaparecido, como borrada, junto con el otro elemento de la invocación: Bismi, en Bismi [A]lläh, 'En el nombre de Dios', en la leyenda de orla del anverso (n. $\left.{ }^{\circ} 78\right)$. También se producen grafias defectuosas de otras palabras contenidas en los textos sagrados ${ }^{49}$. Todo esto, junto con la descuidada ejecución material de muchas de las piezas emirales ${ }^{50}$ podría remitir, en último extremo, y

46 Esto ocurre, por ejemplo, en las monedas n. ${ }^{0 s} 72$ ó 147.

47 Anomalías de este tipo (discordancias de género, o inadecuada declinación, en los numerales) se registran, entre otras, en las monedas n. ${ }^{\text {os }} 17$ ó 59.

48 Corriente, Árabe andalusí y lenguas romances (1992), 92.

49 Errores de diverso tipo, en las inscripciones religiosas, se dan en las monedas n. ${ }^{\text {s }} 4$ ó 13.

50 Se dan, entre otros muchos, los casos de las monedas $n$. $^{0} 39$ (cuño roto de reverso), 76 (primera línea de la inscripción de anverso, quebrada), 90 (doble acuñación del área central del anverso), 99 (ambos cuños defectuosos), 149 (leyenda de orla de anverso, en espiral). 
por la falta relativa de control en la producción de objetos que incluyen la palabra sagrada de Dios, a la situación poco estable ${ }^{51}$ de un Estado, que ${ }^{c} \mathrm{Abd}$ al-Raḥmān II trató de enmendar ${ }^{52}$.

\subsection{Monedas extrapeninsulares}

Otras piezas que destacan dentro del hallazgo es el reducido grupo de las acuñadas fuera de al-Ándalus. Que aparezcan en suelo peninsular monedas acuñadas en Marruecos por los idrīsíes ${ }^{53}$ es un hecho destacable, pero poco novedoso ${ }^{54}$. La presencia anecdótica de la sola moneda 'abbāsí ${ }^{55}$, acuñada en Egipto ( . $^{\circ} 368$ ), es tal vez más significativa porque parece subrayar la orientalización de la España musulmana que, como hemos dicho, impulsó ${ }^{c} A b d$ al-Raḥmān II.

De cualquier modo, la circulación de monedas islámicas por todo el ámbito islámico en la Alta Edad Media no es de extrañar. Hasta en los países escandinavos está documentada la aparición de piezas islámicas ${ }^{56}$. Otra cosa es que, respecto de las cuatro monedas de Domingo Pérez y el modo en que llegaron, sólo quepa lanzar conjeturas. Puede que sean resultado de algún viaje a Oriente por motivos religiosos o científicos, pero también son plausibles otras razones.

Lo que cabe, no obstante, recordar es que los idrīsíes y, en especial los 'abbāsíes, eran, como bien se sabe, dinastías rivales de los omeyas, por razones religiosas ${ }^{57}$ e históricas, respectivamente. Pero

\footnotetext{
51 Sobre la situación política y militar del Emirato en la cora de Elvira, puede verse Álvarez de Morales, «De la conquista musulmana a la abolición del Califato omeya (siglos VIII-XI)» (2000), 145 y ss.

52 Esta hipótesis la ampliamos en nuestro trabajo ya citado, «La mejora epigráfica del 229 h.» (2001).

53 Las monedas idrīíes han dado lugar, entre otros, a dos destacados trabajos: el de Eustache, Corpus des dirhams idrisites et contemporains (1970-71), que es más que lo anunciado en su título, y el estudio de García Arenal y Manzano Moreno: «Idrissisme et villes idrissides» (1995).

54 Canto e Ibrahim, en «Evolución de la moneda andalusí» (1997), p. 78, destacan lo usual de la presencia de piezas idrīíís, aglabíes y fătimíes.

${ }^{55}$ Sobre la amonedación 'abbāsí, puede consultarse una excelente y breve visión de conjunto debida a Bates, «The 'Abbasid coinage system, 833-946» (1996).

${ }_{56}$ Recientemente, una revista de divulgación se hacía eco de estos hallazgos, a través de un artículo acerca de monedas islámicas llevadas hasta Noruega durante los siglos IX y x d.C., de Judith Gabriel, «Among the Norse tribes: The remarkable account of Ibn Fadlan», en ARAMCO World (Houston), 50/6, diciembre de 1999, pp. 36-42.

57 Nos referimos al hecho de que los idrīíes se declarasen 'alíes. En las monedas esto se plasma en la mención sistemática del nombre del imām ${ }^{\mathrm{c}} \mathrm{Alī}$, y de la inclusión, al
} 
eso no parece que impidiese la presencia de sus monedas en al-Ándalus y que acabasen ofreciendo modelos que influirían en el desarrollo de la numismática del Occidente islámico.

\subsection{Circulación y emisión}

En contra de lo que, con algunas excepciones ${ }^{58}$, suele ser norma al describir hallazgos monetarios de este tipo, hemos puesto mucho cuidado en señalar las variantes de las piezas respecto a lo descrito en los corpora anteriores. Y esto, porque el dato de la presencia de determinadas variantes, sobre todo si no están registradas, podría tener su importancia de cara a futuras investigaciones sobre circulación monetaria. Y, en el caso concreto del Emirato, tal vez también para allegar datos que contribuyan a esclarecer el problema planteado más arriba, respecto de la existencia de una sola o más de una ceca emisoras.

En algunos casos la presencia mayoritaria de una variante entre las piezas descritas para cada año se debe simplemente a que se trata de la variante más frecuente en términos absolutos; así ocurre, por ejemplo, en el año 233/847-8. Sin embargo, la simple observación del catálogo que sigue permite afirmar que en este hallazgo tienen presencia significativa, dentro de un mismo año, unas mismas variantes y que faltan otras. Así, por mencionar un año con pocas piezas, en 222/836-7 tenemos la presencia de dos parejas de variantes idénticas,

\footnotetext{
menos en una pieza, del texto ${ }^{c}$ Alī jayru l-nāsi ba da l-nabiyyi kariha man kariha wa-radiya man radī (esto es: « ${ }^{\mathrm{C}} \mathrm{Alī}$ es la mejor de las personas, después del Profeta, moleste a quien moleste, guste a quien guste»), registrado por Eustache: Corpus des dirhams idrisites et contemporains (1970-71), $\mathrm{n}^{\circ}{ }^{\circ} 272$. Las implicaciones religiosas de esta inscripción las analiza Daoudi en Monnaies médias (1987), p. 80, quien llega a la conclusión de que, con semejante declaración, 'Ĩsà bn. Idrīs II, el «monarca» emisor, está haciendo profesión de fe šî́í ${ }^{\prime}$. Este investigador marroquí ofrece, por cierto, de dicha declaración una versión que juzgamos discutible (ibidem): «Ali, le meilleur des hommes après le Prophète. Il aimait et haissait les mêmes gens, choses idées, que lui». De cualquier manera, Mercedes García-Arenal nos hace ver (en comunicación personal) que la caracterización šî́i de los idrīsíes no es aceptada por muchos investigadores. El asunto es materia numismática en

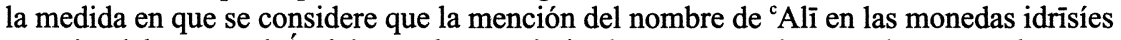
que circulaban por al-Ándalus pudo constituir alguna suerte de precedente para las acuñaciones de subsiguientes dinastías (sunníes) donde se hace mención de personajes carismáticos.

58 Por ejemplo, en el trabajo de Canto García, «Tesoro de moneda emiral, del siglo II de la hégira, conservado en el MAN» (1988b).
} 
no registradas por Miles. Y el hecho se repite en más ocasiones. Esto, ¿a qué se debe?

Si datos similares se confirmaran en otros hallazgos, podría lanzarse la hipótesis de que el ámbito de circulación de las piezas era, al menos en algunos casos, restringido. Sin que podamos precisar más, pues, como decimos, esta información no suele facilitarse en las descripciones de hallazgos, podría pensarse que, si realmente sólo hubo una ceca central durante todo el Emirato, el abastecimiento a las distintas zonas del Estado se realizaba de modo tal que sólo algunas variedades de las piezas emitidas cada año llegaban a lugares concretos. Pero, desde luego, sólo los datos de nuestro hallazgo ofrecen poca base para llegar a conclusiones sólidas. No obstante, aquí tenemos un nuevo indicio que sumar a los anteriores, de que tal vez no hay que descartar la existencia de varias cecas emisoras bajo la denominación de al-Ándalus.

Por otro lado, puede considerarse que los errores en las leyendas son también variantes de las piezas conocidas. Y también a este respecto el hallazgo de Domingo Pérez ofrece indicios de la acumulación, en un mismo ocultamiento, de monedas que repiten un mismo error lingüístico ${ }^{59}$.

\section{Catálogo del hallazgo emiral de Domingo Pérez}

\subsection{Indicaciones sobre el catálogo}

Las denominaciones (siempre dirhames o fragmentos de dirhames), los años de acuñación, la ceca (siempre al-Andalus) y los emires emisores se señalan en grupos para las monedas andalusíes. Individualmente, los datos recogidos son, en este orden: dimensiones, peso, referencia al corpus de moneda emiral más reciente, que sigue siendo el de Miles ${ }^{60} \mathrm{y}$ referencia del MAEGR. Sólo en aquellas monedas la lectura de cuyo año plantea algún problema, hemos especificado el año que les atribuimos y añadimos la abreviatura $l d$, por «lectura difícil/dudosa». En cuanto a las referencias al corpus emiral, y por ahorrar espacio, nos

\footnotetext{
59 Son los dirhames n. ${ }^{\text {os }} 353$ y 354 , en cuya unidad del numeral no se observa la concordancia de género.

60 The Coinage of the Umayyads of Spain (1950).
} 
hemos limitado a dar, para cada pieza, la de Miles, obra que recoge las variedades registradas por Vives y Escudero y otras que a éste le eran desconocidas ${ }^{61}$. Sólo excepcionalmente señalamos otra referencia: la del trabajo de Marinho ${ }^{62}$ sobre el hallazgo del Alentejo, donde se describe una variante no recogida por Miles que coincide con un ejemplar de Domingo Pérez. Y utilizamos, en algunos casos, dos abreviaturas: var., por «variante», y vnr, por «variante no registrada», siempre respecto a Miles, y con indicación de los rasgos distintivos de las piezas así calificadas. Para referirnos a los cuatro sectores epigráficos en que se dividen los dirhames emirales, así como otras muchas monedas árabes medievales, nos servimos de las abreviaturas convencionales, según las cuales $I M$ designa la orla del anverso; $I C$, el área central del anverso; IIM, la orla del reverso y IIC, el área central del reverso ${ }^{63}$. En cuanto a las monedas extrapeninsulares, las referencias las damos por los trabajos de Eustache ${ }^{64}$ y Lavoix ${ }^{65}$.

\subsection{Piezas andalusies}

4.1.1. Dirhames y fragmentos de dirhames datados

cAbd al-Raḥmān I

$150 \mathrm{~h} / 767-8$ d.C.

1. 20 '25 mm. 1'5 g. Miles: 41 var. (IIC: sobre $3 .^{a}$ línea, un solo punto). E14242.

153h /770 d.C.

2. $25^{\prime} 85$ mm. 2'4 g. Miles: 44b. E14243.

154 h/770-1 d.C.

3. 24'65 mm. 1'7 g. Miles: 45. E14244.

${ }^{61}$ Por ejemplo, el dirham $\mathrm{n} .^{\circ} 105$ de esta lista del hallazgo de Domingo Pérez.

62 «Uma prática singular em moedas do Emirado do Ândalus» (1983).

${ }^{63}$ El establecimiento de cuál es el anverso y cuál el reverso, así como la precedencia de las orlas sobre las áreas centrales, lo derivamos de la presencia de la fórmula de incipit tradicional árabe: Bismi [A]lläh ('En el nombre de Dios'], que sirve también como declaración fedataria. Para mayores detalles sobre esto, pueden verse Prieto Vives, «La reforma numismática de los almohades» (1915), p. 14, y Vega Martín, Peña Martín y Feria García, El mensaje de las monedas almohades (en prensa), Capítulo VII.

${ }^{64}$ Corpus des dirhams idrisites et contemporains (1970-71).

${ }^{65}$ Catalogue des monnaies musulmanes de la Bibliothéque Nationale (1887). 


\section{Hišām I}

177 h/793-4 d.C.

4. 23'55 mm. 2'0 g. Miles: 68a. E14246.

5. 28'80 mm. 2'6 g. Miles: 68b. E14245.

\section{Al-Hakam I}

$191 \mathrm{~h} / 806-7$ d.C.

6. 23'10 mm. 1'5 g. Miles: 82b. E14436.

194 h/809-10 d.C.

7. 25'10 mm. 2'1 g. Miles: 85a var. (IA, gráfila: circunferencias sin punto). E14247.

$197 \mathrm{~h} / 812-3$ d.C.

8. 25'50 mm. 2'6 g. Miles: $88 \mathrm{c}$ var. (IC: sobre $3 .^{\mathrm{a}}$ línea, estrella de seis puntas.) E14248.

9. 23'00 mm. 1'9 g. Miles: $88 \mathrm{c}$ var. (IC: sobre $3 .^{\mathrm{a}}$ línea, estrella de seis puntas.) E14249.

199 h/814-5 d.C.

10. 26'10 mm. 2'6 g. Miles: 90f. E14540.

11. 24'85 mm. 2'2 g. Miles: 90f. E14250.

200 h/815-6 d.C.

12. $26^{\prime} 40$ mm. 2'7 g. Miles: 91b. E14320.

13. 24'70 mm. 2'1 g. Miles: 91b. E14251.

201 h/816-7 d.C.

14. 23'05 mm. 1'8 g. Miles: 92c. E14252.

15. 24'70 mm. 2'0 g. Miles: 92d. E14253.

16. 27'15 mm. 2'7 g. Miles: 92d. E14254.

17. 23'30 mm. 1'9 g. Miles: 92d. E14255.

203 h/818-9 d.C.

18. 24'00 mm. 1'9 g. Miles: 94b. E14256.

204 h/819-20 d.C.

19. 26’35 mm. 2'7 g. Miles: 95 . E14258.

20. 21'65 mm. 1'8 g. Miles: 95 . E14260.

21. 26'50 mm. 2'6 g. Miles: 95 . E14259.

206 h/821-2 d.C., año límite entre al-Hakam I y ${ }^{c}$ Abd al-Raḥmān II 22. 23'75 mm. 2'1 g. Miles: 97a. E14261.

23. 24'60 mm. 2'1 g. Miles: 97a. E14686.

24. 23'80 mm. 2'1 g. Miles: 97a. E14262. 


\author{
'Abd al-Raḥmān II \\ 208 h/823-4 d.C. \\ 25. 27 '45 mm. 2'5 g. Miles: 99a. E14267. \\ 26. $27^{\prime} 00 \mathrm{~mm}$. 2'5 g. Miles: $99 \mathrm{c}$ var. (IIC: arriba y abajo, medias lunas); \\ Marinho: 16. E14266.
}

209 h/824-5 d.C.

27. $23^{\prime} 80 \mathrm{~mm}$. 2’0 g. Miles: $100 \mathrm{~b}$ var. (IM: circunferencias solas sin puntos). E14268.

212 h/827-8 d.C.

28. $26^{\prime} 85 \mathrm{~mm} .2^{\prime} 7 \mathrm{~g}$. Miles: 103a. E14269.

213 h/828-9 d.C.

29. 27'10 mm. 2'6 g. Miles: 104d var. (IM: circunferencias con punto; IIC: abajo, punto). E14270.

214 h/829-30 d.C.

30. 22'80 mm. 1'9 g. Miles: 105d var. (IIC: arriba y abajo, punto). E14418.

217 h/832-3 d.C.

31. 24'40 mm. 2'6 g. Miles: 108a var. (estilo B; IIC, arriba y abajo, medias lunas). E14751.

32. $22^{\prime} 70 \mathrm{~mm} .2^{\prime} 1 \mathrm{~g}$. Miles: $108 \mathrm{c}$ var. (IM: circunferencias con punto). E14271.

218 h/833-4 d.C.

33. $22^{\prime} 25 \mathrm{~mm} .1^{\prime} 6 \mathrm{~g}$. Miles: $109 \mathrm{~b}$ var. (IM: circunferencias sin punto.) E14272.

34. 23 '55 mm. 2'0 g. Miles: $109 \mathrm{~b}$ var. (IM: circunferencias sin punto.) E14273.

219 h/834-5 d.C.

35. $26^{\prime} 60 \mathrm{~mm} .2^{\prime} 5$ g. Miles: $110 \mathrm{c}$. E14356.

36. $25^{\prime} 00 \mathrm{~mm}$. 2'2 g. Miles: 110c. E14274.

37. 22'45 mm. 1'8 g. Miles: 110c. E14275.

38. 24'15 mm. 2'1 g. Miles: 110c. E14276.

220 h/835 d.C.

39. 26 '85 mm. 2'6 g. Miles: 111c. E14282.

40. $23^{\prime} 80 \mathrm{~mm}$. 2'0 g. Miles: $111 \mathrm{c}$. E14284.

41. 28 '05 mm. 2'7 g. Miles: 111c ¿var.? (IC: sobre 3. línea, no se aprecia nombre). E14281.

42. 26 '35 mm. 2'5 g. Miles: 111e. E14277.

43. 22 '50 mm. 2'0 g. Miles: 111 e. E14278. 
44. $25^{\prime} 75 \mathrm{~mm}$. 2'1 g. Miles: 111e. E14280.

45. 25'60 mm. 1'9 g. Miles: $111 \mathrm{e}$. E14283.

46. 24'55 mm. 2'2 g. Miles: 111e. E14285.

47. $22^{\prime} 10 \mathrm{~mm} .1^{\prime} 7 \mathrm{~g}$. Miles: $111 \mathrm{e}$. E14286.

48. $25^{\prime} 10 \mathrm{~mm} .2^{\prime} 0 \mathrm{~g}$. Miles: $111 \mathrm{e}$. E14287.

49. 22 '25 mm. 1'5 g. Miles: 111 c o e. E14279.

\section{1 h/835-6 d.C.}

50. $25^{\prime} 00 \mathrm{~mm} .2^{\prime} 0$ g. Miles: $112 \mathrm{a}$ var. (IM: cinco circunferencias; IIC: abajo, marca). E14288.

51. 23'80 mm. 1'8 g. Miles: 112d. E14290.

52. $24^{\prime} 00 \mathrm{~mm}$. 2'0 g. Miles: $112 \mathrm{~d}$. E14291.

53. Fragmento. 25 '50 × 12'85 mm. 1'2 g. Miles: 112 d. E14292.

54. 27'15 mm. 2'7 g. Miles: 112d. E14293.

55. 27’45 mm. 2'5 g. Miles: 112 var. (IIC: abajo, cinco puntos). E14289.

\section{2 h/836-7 d.C.}

56. 27 '40 mm. 2'4 g. Miles: 114a var. (IIC: arriba, punto). E14294. 57. 22'65 mm. 1'8 g. Miles: $114 \mathrm{a}$ var. (IIC: abajo, tres puntos bajando hacia la izquierda). E14297.

58. 22'15 mm. 1'9 g. Miles: 114a var. (IIC: abajo, tres puntos bajando hacia la izquierda). E14300.

59. 25'10 mm. 1'9 g. Miles: $114 \mathrm{c} . \mathrm{E} 14298$.

60. 22'75 mm. 1'8 g. Miles: 114c.E14299.

61. 26'00 mm. 2'5 g. Miles: 114c. E14301.

$62.26^{\prime} 70 \mathrm{~mm} .2^{\prime} 5 \mathrm{~g}$. Miles: $114 \mathrm{c}$ var. (IIC: abajo, puntos en triángulo invertido). E14295.

63. 26’45 mm. 2’3 g. Miles: 114c var. (IIC: abajo, puntos en triángulo invertido). E14296.

64. 24'95 mm. 2'0 g. Miles: 114 var. (IC y IIC: $\sin$ marcas). E14420.

\section{3 h/837-8 d.C.}

65. $26^{\prime} 40 \mathrm{~mm} .2^{\prime 2} 2$ g. Miles: 115a. E14303.

66. $24^{\prime} 20 \mathrm{~mm} .1^{\prime} 8 \mathrm{~g}$. Miles: $115 \mathrm{a}$. E14304.

67. $22^{\prime} 85 \mathrm{~mm}$. 1'6 g. Miles: 115a. E14305.

68. $26^{\prime} 80 \mathrm{~mm}$. 2'3 g. Miles: $115 \mathrm{a}$ var. (IM: seis $-\mathrm{y}$ no cinco- circunferencias con punto). E14306.

69. 24 '80 mm. 2'3 g. Miles: $115 \mathrm{c}$. E14307.

70. $27^{\prime} 40 \mathrm{~mm} .2^{\prime} 5 \mathrm{~g}$. Miles: $115 \mathrm{c}$. E14308.

71. $24^{\prime} 00 \mathrm{~mm}$. 1'8 g. Miles: $115 \mathrm{c}$ ¿var.? (IIC: abajo, no se aprecia nada). E14309. 


\section{4 h/838-9 d.C.}

72. $29^{\prime} 65 \mathrm{~mm}$. 2'6 g. Miles: 116b. E14350.

73. $22^{\prime} 55 \mathrm{~mm}$. 1'4 g. Miles: 116b. E14346.

74. $28^{\prime} 00 \mathrm{~mm} .2^{\prime} 6 \mathrm{~g}$. Miles: 116b. E14310.

75. $27^{\prime} 95 \mathrm{~mm} .2^{\prime} 7 \mathrm{~g}$. Miles: 116b. E14311.

76. $26^{\prime} 25 \mathrm{~mm}$. 2'0 g. Miles: 116b. E14312.

77. 27'55 mm. 2'2 g. Miles: 116b. E14313.

78. $25^{\prime} 90 \mathrm{~mm} .2^{\prime} 5 \mathrm{~g}$. Miles: $116 \mathrm{~b}$. E14314.

79. $25^{\prime} 80 \mathrm{~mm} .2^{\prime} 3 \mathrm{~g}$. Miles: $116 \mathrm{~b}$. E14316.

80. $27^{\prime} 95 \mathrm{~mm}$. 2'6 g. Miles: 116b. E14317.

81. 24'30 mm. 2'1 g. Miles: 116b. E14318.

$82.27 ' 55 \mathrm{~mm} .2^{\prime} 5 \mathrm{~g}$. Miles: $116 \mathrm{~b}$ var. (IIC: arriba, punto; abajo, circunferencia). E14315.

83. 23 ' $10 \mathrm{~mm}$. 1'6 g. Miles: $116 \mathrm{~g}$. E14319.

84. $24^{\prime} 70 \mathrm{~mm}$. 2'0 g. Miles: $116 \mathrm{~g}$. E14324.

\section{5 h/839-40 d.C.}

$85.24^{\prime} 30 \mathrm{~mm}$. 2'0 g. Miles: 117b. E14321.

86. $26^{\prime} 35 \mathrm{~mm} .2^{\prime} 5 \mathrm{~g}$. Miles: $117 \mathrm{~b}$. E14322.

87. $26^{\prime} 45 \mathrm{~mm} .2^{\prime} 4$ g. Miles: $117 \mathrm{~b}$. E14323.

88. $27^{\prime} 10 \mathrm{~mm} .2^{\prime} 5$ g. Miles: $117 \mathrm{~b}$. E14326.

89. 24'30 mm. 1'9 g. Miles: $117 \mathrm{~b}$. E14329.

90. 225 h.(l.d.) $20^{\prime} 15$ mm. 1'4 g. Miles: 117b. E14330.

91. 25'30 mm. 1'9 g. Miles: 117b var. (IIC: arriba, punto, y abajo, círculo pequeño). E14325.

92. 21'35 mm. 1'8 g. Miles: 117b var. (IIC: arriba, nada, y abajo, círculo pequeño). E14327.

93. 22'45 mm. 1'8 g. Miles: 117e var. (IIC: abajo, sólo dos puntos horizontales). E14328.

\section{6 h/840-1 d.C.}

94. 23'50 mm. 1'8 g. Miles: $118 \mathrm{c}$. E14334.

$95.23^{\prime} 90 \mathrm{~mm} .2^{\prime} 0 \mathrm{~g}$. Miles: $118 \mathrm{c} . \mathrm{E} 14335$.

$96.20^{\prime} 70 \mathrm{~mm} .1^{\prime} 3 \mathrm{~g}$. Miles: $118 \mathrm{c}$ var. (IIC: arriba, punto, y abajo, circunferencia). E14337.

97. $25^{\prime} 90 \mathrm{~mm}$. 2'5 g. Miles: $118 \mathrm{c}$ var. (IIC: abajo, tres puntos en triángulo). E14339.

98. $27^{\prime} 10 \mathrm{~mm} .2^{\prime} 6 \mathrm{~g}$. Miles: $118 \mathrm{c}$ var. (IIC: arriba, nada, y abajo, tres puntos en línea). E14340.

99. 27'90 mm. 2'6 g. Miles: $118 \mathrm{c}$ var. (IIC: arriba, nada). E14343.

100. $26^{\prime} 40 \mathrm{~mm}$. 2'5 g. Miles: $118 \mathrm{c}+$ d. E14333.

101. 25'65 mm. 2'1 g. Miles: $118 \mathrm{~d}$. E14331.

102. $24^{\prime} 00 \mathrm{~mm}$. 2’0 g. Miles: $118 \mathrm{~d}$. E14336. 
103. 23'50 mm. 2'0 g. Miles: $118 \mathrm{~d}$. E14344.

104. 22'30 mm. 1'0 g. Miles: $118 \mathrm{~d}$ var. (IIC: arriba, nada). E14342.

105. $26^{\prime} 80 \mathrm{~mm}$. 2'5 g. Miles: $118 \mathrm{e}$. E14338.

106. $29^{\prime} 35 \mathrm{~mm} .2^{\prime} 5 \mathrm{~g}$. Miles: $118 \mathrm{f}$ var. (IIC: abajo, tres puntos en triángulo invertido). E14341.

107. 28 '65 mm. 2'5 g. Miles: 118j. E14332.

\section{7 h/841-2 d.C.}

108. 23'75 mm. 1'6 g. Miles: 119b. E14263.

109. 27'50 mm. 2'4 g. Miles: $119 \mathrm{~b}$. E14347.

110. 23'10 mm. 1'9 g. Miles: $119 \mathrm{~b}$. E14348.

111. $27^{\prime} 00 \mathrm{~mm} .2^{\prime} 6 \mathrm{~g}$. Miles: $119 \mathrm{~b}$. E14349.

112. 23'00 mm. 1'4 g. Miles: $119 \mathrm{~g}$. E14345.

113. 22 ¿7? 24'50 mm. 1'8 g. Miles: ¿119 g?. E14264.

\section{8 h/842-3 d.C.}

114. 27'15 mm. 2'3 g. Miles: 120b. E14351.

115. $25^{\prime} 00 \mathrm{~mm}$. 2'6 g. Miles: 120d var. (IC: abajo, nada). E14352.

116. $27^{\prime} 20 \mathrm{~mm} .2^{\prime} 6 \mathrm{~g}$. Miles: $120 \mathrm{e}$. E14353.

117. $24^{\prime} 80 \mathrm{~mm}$. 2'2 g. Miles: $120 \mathrm{e}$. E14354.

118. $26^{\prime} 90 \mathrm{~mm}$. 2'6 g. Miles: $120 \mathrm{e}$. E14355.

119. $25^{\prime} 80 \mathrm{~mm}$. 2’4 g. Miles: $120 \mathrm{e}$ var. (IIC: arriba, punto). E14673.

\section{9 h/843-4 d.C.}

120. $24^{\prime} 90$ mm. 2'5 g. Miles: 121 e. E14357.

121. $25^{\prime} 10 \mathrm{~mm}$. 2'8 g. Miles: $121 \mathrm{e}$. E14358.

122. 22'85 mm. 2'3 g. Miles: 121e var. (IIC: abajo, circunferencia). E14359.

123. $26^{\prime} 00 \mathrm{~mm}$. 2'7 g. Miles: $121 \mathrm{f}$. E14362.

124. $26^{\prime} 90 \mathrm{~mm}$. 2'7 g. Miles: 121f. E14363.

125. 23'80 mm. 1'9 g. Miles: $121 \mathrm{f}$. E14364.

126. $22^{\prime} 95 \mathrm{~mm} .2^{\prime} 1 \mathrm{~g}$. Miles: $121 \mathrm{f}$ var. (IIC: arriba, circunferencia pequeña). E14360.

127. $24^{\prime} 70$ mm. 2'6 g. Miles: 121 i. E14361.

\section{0 h/844-5 d.C.}

128. $26^{\prime} 00 \mathrm{~mm} .2^{\prime} 4 \mathrm{~g}$. Miles: $122 \mathrm{e}$. E14365.

129. $21^{\prime} 90 \mathrm{~mm} .1^{\prime} 7 \mathrm{~g}$. Miles: $122 \mathrm{~h}$. E14367.

130. 22'35 mm. 1'6 g. Miles: $122 \mathrm{~h}$. E14368.

131. 24'00 mm. 2'6 g. Miles: 122h. E14369.

132. 23'95 mm. 2'5 g. Miles: $122 \mathrm{~h}$. E14370.

133. 21'30 mm. 1'8 g. Miles: 122 h. E14371.

134. Fragmento. 230 (ld) h. $24^{\prime} 45 \times 11^{\prime} 90 \mathrm{~mm}$. 1'0 g. Miles: $122 \mathrm{e}$ o h. E14373. 
135. 22'00 mm. 1'7 g. Miles 122B vnr (IIC: arriba, circunferencia, y abajo, signo). E14366.

\section{1 h/845-6 d.C.}

136. 25'70 mm. 2'3 g. Miles: 123a. E14375.

137. $25^{\prime} 80 \mathrm{~mm}$. 2'6 g. Miles: 123a. E14376.

138. 26’35 mm. 2'6 g. Miles: 123a. E14377.

139. $24^{\prime} 40 \mathrm{~mm}$. 2'2 g. Miles: 123a. E14378.

140. 25'45 mm. 2'6 g. Miles: 123a. E14379.

141. 23'95 mm. 2'0 g. Miles: 123a. E14380.

142. $26^{\prime} 90 \mathrm{~mm}$. 2'6 g. Miles: 123a. E14381.

143. 231 (ld) h. 21'70 mm. 1'7 g. Miles: 123a. E14683.

144. $20^{\prime} 90 \mathrm{~mm} .1^{\prime} 7 \mathrm{~g}$. Miles: $123 \mathrm{a}$. E14382.

145. 22 '20 mm. 1'8 g. Miles: 123a. E14383.

146. 22'30 mm. 1'6 g. Miles: 123a. E14384.

147. $26^{\prime} 90 \mathrm{~mm} .2^{\prime} 4 \mathrm{~g}$. Miles: $123 \mathrm{vnr}$ (IC: nada). E14385.

148. Fragmento. 243 (ld) h. $18^{\prime} 80 \times 10^{\prime} 45$ mm. 0’5 g. Miles: 123 . E14710

\section{2 h/846-7 d.C.}

149. 29'50 mm. 2'6 g. Miles: 124a. E14374.

150. $24^{\prime} 00 \mathrm{~mm}$. 2'1 g. Miles: 124a. E14391.

151. 23'80 mm. 2'1 g. Miles: 124b. E14386.

152. 24'10 mm. 2'5 g. Miles: $124 \mathrm{~b}$. E14387.

153. 25 '55 mm. 2'5 g. Miles: $124 \mathrm{~b}$. E14388.

154. 21'35 mm. 1'4 g. Miles: 124b. E14389.

155. 21'75 mm. 1'6 g. Miles: 124b. E14390.

156. 23 ¿2?. $24^{\prime} 70 \mathrm{~mm}$., 2'1 g. Miles: $124 \mathrm{vnr}$ (A; IIC: arriba, puntos en triángulo; abajo, aspa). E14392.

\section{3 h/847-8 d.C.}

157. Fragmento. 23 ' $10 \times 17^{\prime} 85 \mathrm{~mm}$. 1'2 g. Miles: 125a. E14711.

158. $23^{\prime} 70 \mathrm{~mm} .1^{\prime} 8 \mathrm{~g}$. Miles: $125 \mathrm{~b}$. E14393.

159. $25^{\prime} 00 \mathrm{~mm}$. 2’0 g. Miles: $125 \mathrm{~b}$. E14394.

160. 21'30 mm. 1'4 g. Miles: 125b. E14265.

161. 22'90 mm. 2'0 g. Miles: $125 \mathrm{~b}$. E14257.

162. $27^{\prime} 75 \mathrm{~mm}$. 2’4 g. Miles: $125 \mathrm{~b}$. E14703.

163. 24'85 mm. 2'3 g. Miles: $125 \mathrm{~b}$. E14396.

164. $26^{\prime} 60 \mathrm{~mm}$. 2'6 g. Miles: $125 \mathrm{~b}$. E14397.

165. 27'95 mm. 2'3 g. Miles: 125b. E14398.

166. $26^{\prime} 05 \mathrm{~mm}$. 2'5 g. Miles: $125 \mathrm{~b}$. E14399.

167. $24^{\prime} 60 \mathrm{~mm}$. 2'4 g. Miles: $125 \mathrm{~b}$. E14400.

168. Fragmento. $25^{\prime} 20 \times 16^{\prime} 95 \mathrm{~mm}$. 1'4 g. Miles: $125 \mathrm{~b}$. E14401.

169. 24’30 mm. 2'1 g. Miles: $125 b$. E14402. 
170. 26 '20 mm. 2'5 g. Miles: $125 \mathrm{~b}$. E14403.

171. 23'60 mm. 2'1 g. Miles: $125 \mathrm{~b}$. E14404.

172. $26^{\prime} 00 \mathrm{~mm}$. 2'4 g. Miles: $125 \mathrm{~b}$. E14405.

173. 22'95 mm. 1'6 g. Miles: 125b. E14406.

174. 19'85 mm. 1'3 g. Miles: $125 \mathrm{~b}$. E14407.

175. Fragmento. $21^{\prime} 95 \times 13^{\prime} 70 \mathrm{~mm}, 0^{\prime} 9 \mathrm{~g}$. Miles: $125 \mathrm{c}$. E14395.

\section{4 h/848-9 d.C.}

176. 24 ' 45 mm. 2'7 g. Miles: 126a. E14408.

177. 24'50 mm. 2'0 g. Miles: 126a. E14409.

178. 24'15 mm. 2'0 g. Miles: 126a. E14689.

179. 23'55 mm. 2'0 g. Miles: 126b. E14410.

180. 24'20 mm. 2'3 g. Miles: 126b. E14411.

181. $23^{\prime} 70 \mathrm{~mm}$. 2'2 g. Miles: $126 \mathrm{~b}$. E14412.

182. $24^{\prime} 50 \mathrm{~mm}$. 2'0 g. Miles: $126 \mathrm{~b}$. E14413.

183. 25’30 mm. 2’0 g. Miles: 126b. E14414.

185. $25^{\prime} 55 \mathrm{~mm}$. 2'2 g. Miles: $126 \mathrm{~b}$. E14416.

186. 23'45 mm. 2'0 g. Miles: 126b. E14417.

187. 22'55 mm. 1'6 g. Miles: 126b.E14419.

188. 234 (ld) h. $26^{\prime} 70$ mm. 2'3 g. Miles: $126 \mathrm{~b}$. E14422.

189. $22^{\prime} 70 \mathrm{~mm}$. 1'8 g. Miles: $126 \mathrm{~b}+\mathrm{c}$. E14415.

190. $25^{\prime} 95 \mathrm{~mm}$. 2’0 g. Miles: $126 \mathrm{~B}$ vnr (IC: nada, y IIC: arriba, un punto, y abajo, tres en triángulo invertido). E14421.

\section{5 h/849-50 d.C.}

191. 23'10 mm. 2'0 g. Miles: 127 a. E14423.

192. $22^{\prime} 45 \mathrm{~mm}$. 1'8 g. Miles: $127 \mathrm{a}$ var. (IIC: abajo, marca indefinida). E14684.

193. $25^{\prime} 90 \mathrm{~mm}$. 2’3 g. Miles: $127 \mathrm{a}+\mathrm{d}$ (IC: nada, y IIC: circunferencia pequeña. E14435.

194. 23'65 mm. 2'1 g. Miles: $127 \mathrm{~b}$. E14424.

195. 24'30 mm. 1'9 g. Miles: $127 \mathrm{~b}$. E14425.

196. 23'45 mm. 1'9 g. Miles: 127b. E14426.

197. 23'90 mm. 2'1 g. Miles: $127 \mathrm{~b}$. E14433.

198. 23 ' $40 \mathrm{~mm}$. 2'2 g. Miles: $127 \mathrm{~b}+\mathrm{d}$ (IC: abajo, letra 'ayn, y IIC: abajo, punto). E14427.

199. $22^{\prime} 70 \mathrm{~mm} .2^{\prime} 0 \mathrm{~g}$. Miles: $127 \mathrm{~b}+\mathrm{d}$ (IC: abajo, letra ${ }^{c}$ ayn, y IIC: abajo, círculo). E14428.

200. $26^{\prime} 85 \mathrm{~mm}$. 2'6 g. Miles: $127 \mathrm{~b}+\mathrm{d}$ (IC: abajo: letra 'ayn, y IIC: abajo, circunferencia).E14429.

201. 27'25 mm. 2'6 g. Miles: 127 c. E14430.

202. 27'60 mm. 2'6 g. Miles: $127 \mathrm{c}$. E14431.

203. 235 (ld) h. 22'90 mm. 1'8 g. Miles: 127c. E14432. 
204. $24^{\prime} 00$ mm. 2'1 g. Miles: $127 \mathrm{c}+\mathrm{d}$ (IC: abajo, letra $h \bar{a} '$ ' y IIC: abajo, círculo pequeño). E14434.

\section{6 h/850-1 d.C.}

205. 24'10 mm. 2’0 g. Miles: 128a. E14437.

206. 24'20 mm. 2'2 g. Miles: 128 a. E14438.

207. 24'20 mm. 1'9 g. Miles: 128a. E14693.

208. Fragmento. $22^{\prime} 95 \times 15^{\prime} 55 \mathrm{~mm}$. 1'4 g. Miles: 128a. E14714.

209. $25^{\prime} 65 \mathrm{~mm} .2^{\prime} 2$ g. Miles: $128 \mathrm{~b}$. E14440.

210. 23'70 mm. 2'3 g. Miles: 128 b. E14445.

211. 24'55 mm. 2'2 g. Miles: 128b. E14442.

212. Fragmento. 23 '73 × 13'50 mm. 0'9 g. Miles: $128 \mathrm{~b}$. E14443.

213. $22^{\prime} 20 \mathrm{~mm}$. 1'9 g. Miles: $128 \mathrm{~b}$ var. (IC: abajo, dos puntos en diagonal hacia la derecha, y IIC: abajo, marca indefinida). E14439.

214. $26^{\prime} 80 \mathrm{~mm}$. 2’3 g. Miles: 128B vnr (IC: nada, y IIC: abajo, marca indefinida). E14441.

215. $25^{\prime} 80 \mathrm{~mm}$. 2'0 g. Miles: 128B vnr (IC: nada, y IIC: arriba, punto, y abajo, punto); Rodrigues Marinho: 56. E14649.

216. 23'80 mm. 1'8 g. Miles: 128B vnr (IC: nada, y IIC: arriba, punto, y abajo, punto); Rodrigues Marinho: 56. E14444.

217. 23 '30 mm. 2'1 g. Miles: 128B vnr (IC: nada, y IIC: abajo, círculo pequeño). E14446.

\section{7 h/851-2 d.C.}

218. 25 '35 mm. 2'6 g. Miles: 129a var. (IM: sin punto sobre duriba, y IIC: arriba, punto, y abajo, circulito). E14462.

219. 23'10 mm. 2'0 g. Miles: $129 \mathrm{a}+\mathrm{b}$ (IM: punto sobre $h \bar{a} \underline{d} \bar{a}$, y IIC: nada). E14452.

220. 27'30 mm. 2'6 g. Miles: 129a + b (IM: puntos sobre duriba y hād $\bar{a}$; IC: abajo, punto, y IIC: nada). E14453.

221. 22'40 mm. 1'9 g. Miles: 129a + b (IM: puntos sobre duriba y hädāa; IC: abajo, punto, y IIC: abajo, circulito). E14454.

222. 23'55 mm. 1'8 g. Miles: $129 \mathrm{a}+\mathrm{b}$ (IM: circunferencias sin punto, $\mathrm{y}$ puntos sobre duriba y $h \bar{a} \underline{d} \bar{a}$; IC: abajo, punto, y IIC: abajo, punto). E14455.

223. 23 '90 mm, 2'0 g. Miles: 129a + b (IM: circunferencias con punto; IM: punto sobre duriba; IC: nada, y IIC: arriba, punto, y abajo, marca indefinida). E14459.

224. 22'45 mm. 1'9 g. Miles: 129a + b (IM: punto sobre duriba; IC: abajo, punto, y IIC: arriba, nada, y abajo, círculo pequeño). E14480.

225. 22'35 mm. 1'7 g. Miles: $129 \mathrm{a}+\mathrm{b}$ (IM: puntos sobre duriba y häda $\bar{a}$; IC: abajo, punto, y IIC: nada). E14480. 
226. 22 '75 mm. 1'8 g. Miles: $129 \mathrm{a}+\mathrm{j}$ (IM: puntos sobre duriba y häd̆ä; IC: sobre tercera línea, estrella, y IIC: arriba, punto, y abajo, dos puntos horizontales). E14464.

227. $25^{\prime} 20 \mathrm{~mm} .2^{\prime} 4 \mathrm{~g}$. Miles: $129 \mathrm{a}+\mathrm{k}$ (IM: punto sobre duriba; IC: sobre $3 .^{a}$ línea, estrella, y IC: arriba, círculo pequeño, y abajo, tres puntos en triángulo). E14467.

228. 24'10 mm. 2'1 g. Miles: $129 \mathrm{a}+\mathrm{k}$ (IM: punto sobre duriba; IC: sobre

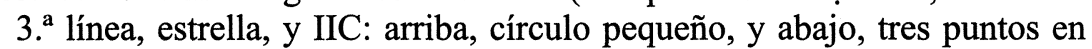
triángulo). E14469.

229. 22'65 mm. 1'7 g. Miles: 129a + 1 (IM: punto sobre $h \bar{a} \underline{d} \bar{a}$; IC: nada, y IIC: arriba, punto, y abajo, tres puntos en triángulo invertido). E14475.

230. $21^{\prime} 90 \mathrm{~mm}$. 1'4 g. Miles: $129 \mathrm{~b}$. E14449.

231. $22^{\prime} 70 \mathrm{~mm}$. 1'9 g. Miles: $129 \mathrm{~b}$. E14451.

232. 237 (ld) h. 23'80 mm. 1'8 g. Miles: 129b. E14447.

233. $23^{\prime} 00 \mathrm{~mm}$. 1'9 g. Miles: $129 \mathrm{~b}$ var. (IC: abajo, dos puntos horizontales separados). E14448.

234. 21'95 mm. 1'6 g. Miles: 129b var. (IM: sin punto sobre duriba, y IC: abajo, dos puntos horizontales separados). E14450.

235. 24'50 mm. 2'2 g. Miles: $129 \mathrm{~b}+\mathrm{i}$ (IM: circunferencias con punto; punto sobre duriba; IC: sobre 3. ${ }^{\mathrm{a}}$ línea, estrella, y IIC: arriba, punto, y abajo, marca indefinida). E14461.

236. 23'45 mm. 1'7 g. Miles: $129 \mathrm{~b}+\mathrm{j}$ (IM: punto sobre duriba; IC: abajo, punto, y IIC: arriba, punto, y abajo, dos puntos horizontales). E14465.

237. 25'30 mm. 2'1 g. Miles: $129 \mathrm{~b}+1$ (IM: puntos sobre duriba y hāda $\bar{a}$; IC: abajo, punto, y IIC: arriba, punto, y abajo, tres puntos en triángulo, sobre vértice). E14478.

238. $27^{\prime} 45 \mathrm{~mm} .2^{\prime} 1 \mathrm{~g}$. Miles: 129e var. (IC: sobre 3. ${ }^{\mathrm{a}}$ línea, nada). E14456.

239. $24^{\prime} 60 \mathrm{~mm}$. 1'9 g. Miles: $129 \mathrm{e}$ var. (IM: circunferencias con punto). E14457.

240. $24^{\prime} 80 \mathrm{~mm}$. 2’2 g. Miles: $129 \mathrm{e}$ var. (IA, gráfila, circunferencias con punto, y IIC: arriba, media luna hacia arriba con punto, y abajo, media luna hacia abajo con punto). E14458.

241. 24'10 mm. 2’0 g. Miles: $129 \mathrm{i}$ var. (IM: punto sobre $h \bar{a} d \bar{d} \bar{a}$ ). E14460.

242. $24^{\prime} 50 \mathrm{~mm}$. 2'3 g. Miles: $129 \mathrm{k}$. E14463.

243. 23'60 mm. 2'0 g. Miles: 129k. E14466.

244. $24^{\prime} 00 \mathrm{~mm}$. 1'8 g. Miles: $129 \mathrm{k}$. E14468.

245. 237 (ld) h. 22'90 mm. 1'7 g. BC-. Miles: 129k var. (IC: sobre 3. ${ }^{a}$ línea, sin estrella, y IIC: arriba, nada). E14482.

246. 23'75 mm. 2'0 g. Miles: 1291. E14470.

247. $23^{\prime} 70 \mathrm{~mm}$. 2'1 g. Miles: 1291 . E14471.

248. $25^{\prime} 10 \mathrm{~mm}$. 2'0 g. Miles: 1291. E14472.

249. 23'90 mm. 2'0 g. Miles: 1291. E14473. 
250. 23'70 mm. 1'9 g. Miles: 1291. E14476.

$251.23^{\prime} 70 \mathrm{~mm} .1^{\prime} 7 \mathrm{~g}$. Miles: 1291 var. (IC: sobre 3. ${ }^{\mathrm{a}}$ línea, nada). E14474.

252. 24'00 mm. 1'9 g. Miles: 129A vnr. (IA, gráfila: círculos; IM: sin punto sobre duriba; IC: abajo, punto, y IIC: arriba, punto, y abajo, dos puntos). E14477.

253. 24'25 mm. 1'9 g. Miles 129A vnr (IA, gráfila: circunferencias grandes con punto; IM: sin puntos; IC: sin marcas, y IIC: arriba, nada, y abajo, punto). E14479.

254. 23 ¿7? h. $25^{\prime} 80 \mathrm{~mm} .1^{\prime} 9$ g. Miles: ¿129? E14302.

\section{Año límite (entre 'Abd al-Raḥmān II y Muḥammad I)}

238 h/852-3 d.C.

255. 26 '25 mm. 2'1 g. Miles: 130a. E14688.

256. $25^{\prime} 40 \mathrm{~mm}$. 2'1 g. Miles: 130a. E14702.

257. $26^{\prime} 00 \mathrm{~mm}$. 2'1 g. Miles: 130a. E14484.

258. 23'65 mm. 1'8 g. Miles: 130a. E14485.

259. 22'20 mm. 1'5 g. Miles: 130a. E14486.

260. $26^{\prime} 00 \mathrm{~mm}$. 2'1 g. Miles: $130 \mathrm{a}+\mathrm{b}$ (IA, gráfila: circunferencias con punto; IC: nada, y IIC: nada). E14483.

$261.24 ’ 25 \mathrm{~mm}$. 1’8 g. Miles: $130 \mathrm{a}+\mathrm{b}$ (IA, gráfila: circunferencias con punto; IC: nada, y IIC: nada). E14690.

262. 238 (ld) h. $25^{\prime} 55 \mathrm{~mm} .1$ '4 g. Miles: $130 \mathrm{a}+\mathrm{b}$ (IA, gráfila: circunferencias grandes con punto; IC: nada, y IIC: nada). E14515.

263. $22^{\prime} 50 \mathrm{~mm}$. 2’0 g. Miles: 130b. E14522.

264. 23'50 mm. 1'6 g. Miles: 130b var. (IC: abajo, punto). E14487.

265. 25 '20 mm. 2’0 g. Miles: 130b, j o 1 (IC: sobre 3. ${ }^{\mathrm{a}}$ línea, marca borrada o inexistente). E14521.

266. 22 '15 mm. 1'3 g. Miles: 130c. E14493.

267. $22^{\prime} 25 \mathrm{~mm}$. 1'9 g. Miles: 130c. E14491.

268. 24'00 mm. 2'1 g. Miles: 130c var. (IM: circunferencias con punto, de una en una). E14488.

269. 24'80 mm. 2'1 g. Miles: 130c var. (IM: circunferencias con punto, de una en una). E14692.

270. 24'75 mm. 2'1 g. Miles: 130c var. (IIC: arriba, dos puntos). E14492.

271. 23'35 mm. 1'7 g. Miles: 130e. E14681.

272. 23'95 mm. 1'9 g. Miles: 130e. E14494.

273. 24'15 mm. 1'7 g. Miles: 130e. E14523.

274. 238 (ld) h. 26’85 mm. 2'6 g. Miles: 130g. E14495.

275. 24 '20 mm. 1'8 g. Miles: $130 \mathrm{~g}$. E14497.

276. 27 '35 mm. 2'7 g. Miles: $130 \mathrm{~g}$. E14498.

277. 24'90 mm. 2'0 g. Miles: $130 \mathrm{~g}$. E14499.

278. $24^{\prime} 60$ mm. 2'2 g. Miles: 130g. E14505. 
279. 24'35 mm. 2'2 g. Miles: 130g. E14507.

280. $22^{\prime} 75 \mathrm{~mm} .1$ '7 g. Miles 130g. E14508.

281. $24^{\prime} 10 \mathrm{~mm}$. 2'0 g. Miles: $130 \mathrm{~g}$. E14510.

282. 238 (ld) h. $26^{\prime} 60 \mathrm{~mm}$. $2^{\prime} 0$ g. Miles: $130 \mathrm{~g}$. E14511.

283. $26^{\prime} 95 \mathrm{~mm}$. 2'3 g. Miles: $130 \mathrm{~g}$. E14512.

284. 25'50 mm. 2'1 g. Miles: $130 \mathrm{~g}$ var. (IC: sobre 3. ${ }^{\mathrm{a}}$ línea, dos puntos horizontales). E14506.

285. 24 '40 mm. 2'0 g. Miles: $130 \mathrm{~g}$ var. (IM: punto sobre Alläh). E14496.

286. $25^{\prime} 70 \mathrm{~mm}$. 2'2 g. Miles: $130 \mathrm{~g}$ var. (IM: punto sobre Alläh). E14509.

287. 238 (ld) h. 23'55 mm. 2'2 g. Miles: 130g var. (IM: punto sobre Alläh). E14513.

288. 238 (ld) h. 21'95 mm. 2'1 g. Miles: 130g var. (IM: punto sobre Alläh). E14514.

289. 22'65 mm. 1'8 g. Miles: 130j. E14517.

290. 22 ' $80 \mathrm{~mm}$. 1'7 g. Miles: 130 j. E14518.

291. $23^{\prime} 95 \mathrm{~mm}$. 1'9 g. Miles: $130 \mathrm{j}$. E14519.

292. $21^{\prime} 70 \mathrm{~mm}$. 1'8 g. Miles: 130 j var. (IM: circunferencias con punto, de una en una). E14516.

293. 27 '10 mm. 2'3 g. Miles: 130A vnr. (IM: circunferencias con punto, de una en una; sin puntos sobre la leyenda, y IC: sobre 3. ${ }^{a}$ línea, punto; IIC: sólo punto central). E14520.

294. 23'65 mm. 2'1 g. Miles: $130 \mathrm{vnr}$ (IC: sobre 3. línea, dos puntos horizontales). E14489.

295. 21 '55 mm. 1'4 g. Miles: $130 \mathrm{vnr}$ (IC: sobre $3 .^{\mathrm{a}}$ línea, dos puntos horizontales). E14490.

\section{Muhammad I}

239 h/853-4 d.C.

296. 26 '20 mm. 2'7 g. Miles: 131 a. E14524.

297. $27 ’ 30 \mathrm{~mm}$. 2’2 g. Miles: 131a. E14525.

298. 22'45 mm. 1'9 g. Miles: 131a. E14526.

299. $22^{\prime} 95 \mathrm{~mm}$. 1'7 g. Miles: 131a. E14647.

300. 24'00 mm. 2'2 g. Miles: 131a. E14648.

301. $24^{\prime} 00 \mathrm{~mm}$. 2'0 g. Miles: 131a. E14527.

302. 23'70 mm. 1'7 g. Miles: 131a. E14750.

303. $28^{\prime} 65 \mathrm{~mm}$. 2'6 g. Miles: 131a. E14528.

304. 23'00 mm. 1'6 g. Miles: 131a. E14529.

305. 21'90 mm. 1'5 g. Miles: 131a. E14691.

306. 24 '65 mm. 1'8 g. Miles: 131a. E14697.

307. 239 (ld) h. 26'10 mm. 2'5 g. Miles: 131 a var. (IIC: arriba, circunferencia). E14530. 
308. 23 '50 mm. 1'8 g. Miles: 131a var. (IIC: arriba, círculo pequeño). E14531.

309. 24’35 mm. 2'1 g. Miles: 131a var. (IIC: arriba, punto). E14532.

310. $27^{\prime} 00 \mathrm{~mm}$. 1'8 g. Miles: 131a var. (IIC: arriba, circunferencia). E14533.

311. $24^{\prime} 00 \mathrm{~mm} .1^{\prime} 9 \mathrm{~g}$. Miles: 131a var. (IIC: arriba, circunferencia). E14534.

312. $27^{\prime} 65$ mm. 2'7 g. Miles: $131 \mathrm{~g}$. E14535.

313. $26^{\prime} 00 \mathrm{~mm} .2^{\prime} 7 \mathrm{~g}$. Miles: $131 \mathrm{~g}$ var. (IM: sin punto sobre duriba, y IC: abajo, nada). E14536.

314. $26^{\prime} 05 \mathrm{~mm} .2^{\prime} 5 \mathrm{~g}$. Miles: $131 \mathrm{~g}$ var. (IM: sin punto sobre duriba, y IC: abajo, nada). E14537.

$315.23^{\prime} 55 \mathrm{~mm}$. 2’0 g. Miles: $131 \mathrm{~g}$ var. (IM: sin punto sobre duriba, y IC: abajo, nada). E14538.

316. $24^{\prime} 90 \mathrm{~mm}$. 2'0 g. Miles: $131 \mathrm{j}$ var. (IIC: abajo, puntos en triángulo invertido). E14539.

240 h/854-5 d.C.

317. $25^{\prime} 00 \mathrm{~mm}$. 1'9 g. Miles: 132a. E14696.

318. 27'10 mm. 2'5 g. Miles: 132a. E14650.

319. 24'30 mm. 2'0 g. Miles: 132a. E14651.

320. $25^{\prime} 10 \mathrm{~mm}$. 2'1 g. Miles: $132 \mathrm{e}$. E14682.

321. $26^{\prime} 50 \mathrm{~mm}$. 2'6 g. Miles: $132 \mathrm{~g}$. E14694.

322. $27^{\prime} 60 \mathrm{~mm}$. 2'5 g. Miles: $132 \mathrm{~g}$. E14695.

323. $25^{\prime} 45 \mathrm{~mm}$. 1'9 g. Miles: $132 \mathrm{~g}$. E14652.

324. $25^{\prime} 75 \mathrm{~mm} .2^{\prime} 7 \mathrm{~g}$. Miles: $132 \mathrm{~g}$. E14653.

325. $26^{\prime} 25 \mathrm{~mm}$. 2'6 g. Miles: 132g. E14654.

326. $27 ' 35 \mathrm{~mm}$. 2'5 g. Miles: 132g. E14655.

327. $27^{\prime} 35 \mathrm{~mm}$. 2’0 g. Miles: $132 \mathrm{~g}$. E14656.

328. 26'50 mm. 2'6 g. Miles: $132 \mathrm{~g}$. E14657.

329. $26^{\prime} 55 \mathrm{~mm}$. 2'6 g. Miles: 132g. E14660.

330. 27'55 mm. 2'7 g. Miles: 132g. E14662.

\section{1 h/855-6 d.C.}

331. 26'75 mm. 2'7 g. Miles: $133 \mathrm{c}$. E14663. 332. 26 '35 mm. 2'6 g. Miles: 133c. E14658. 333. $27^{\prime} 15 \mathrm{~mm}$. 2'7 g. Miles: 133c. E14666. 334. 26'40 mm. 2'7 g. Miles: $133 \mathrm{c}$. E14667. 335. 26'55 mm. 2'6 g. Miles: 133c. E14668. 336. $28^{\prime} 15 \mathrm{~mm}$. 2'5 g. Miles: 133c. E14669. 337. $25^{\prime} 90$ mm. 1'8 g. Miles: 133c. E14670. 338. 27'00 mm. 2'4 g. Miles: 133c. E14698. 
339. $24^{\prime} 50 \mathrm{~mm} .2^{\prime} 0 \mathrm{~g}$. Miles: $133 \mathrm{c}$ var. (IIC: abajo, izquierda, marca indefinida). E14661.

340. 26'15 mm. 2’2 g. Miles: $133 \mathrm{c}$ var. (IIC: abajo, izquierda, marca indefinida). E14659.

341. $26^{\prime} 85 \mathrm{~mm}$. 2'6 g. Miles: $133 \mathrm{c}$ var. (IIC: arriba, marca indefinida, tal vez estrella). E14664.

342. $25^{\prime} 95 \mathrm{~mm}$. 2'6 g. Miles: $133 \mathrm{c}$ var. (IIC: arriba, marca indefinida, tal vez estrella). E14665.

343. $27^{\prime} 15$ mm. 2'7 g. Miles: 133f. E14671.

344. 241 (ld) h. 23'65 mm. 2'2 g. Miles: 133f. E14699.

345. $25^{\prime} 75 \mathrm{~mm} .2^{\prime} 3 \mathrm{~g}$. Miles: 133A vnr (IM: cinco círculos entre dos puntos; IC: nada, y IIC: arriba, tres puntos, y abajo, marca indefinida). E14672.

\section{2/856-7}

346. 27'40 mm. 2'6 g. Miles: 134f. E14674.

347. 26 '20 mm. 2'8 g. Miles: 134f. E14675.

348. 26'50 mm. 2'6 g. Miles: 134f. E14676.

349. $26^{\prime} 35 \mathrm{~mm}$. 2'7 g. Miles. 134f. E14677.

350. $26^{\prime} 35 \mathrm{~mm} .2^{\prime} 4 \mathrm{~g}$. Miles: $134 \mathrm{f}$. E14678.

351. $27^{\prime} 30 \mathrm{~mm}$. 2'6 g. Miles: 134f. E14680.

352. $29^{\prime} 35 \mathrm{~mm}$. 2'5 g. Miles: $134 \mathrm{f}$. E14685.

353. $27^{\prime} 20 \mathrm{~mm}$. 2'6 g. Miles: $134 \mathrm{f}$. E14700.

354. 27'20 mm. 2'4 g. Miles: 134f. E14705.

355. 242 (ld) h. 26’35 mm. 2'5 g. Miles: 134f. E14687.

356. 242 (ld) h. $27^{\prime} 30$ mm. 2'2 g. Miles: 134f. E14701.

357. 27’60 mm. 2'6 g. Miles: 134B vnr (IC: abajo, estrella, y IIC: sólo punto central). E14679.

\subsubsection{Dirhames y fragmentos de dirhames sin datar}

358. 233 ó 236 h. $23^{\prime} 00$ mm. 1’7 g. Miles: 125b ó 128b. E14704.

359. $23 \mathrm{X}$ h. $25^{\prime} 00 \mathrm{~mm}$. 2'1 g. Miles: A. E14706.

360. Fragmento. $2 X X$ h. 23'60 × 10'75 mm. 1'9 g. Miles: B. E14709.

361. Fragmento. XXX h. $21^{\prime} 75 \times 12^{\prime} 30 \mathrm{~mm}$. 0'8 g. Miles: B. E14707.

362. Fragmento. XXX h. 26'40 × 13'55 mm. 1'2 g. Miles: A. E14708.

363. Fragmento. XXX h. $24^{\prime} 45 \times 16^{\prime} 40 \mathrm{~mm}$. 1'3 g. Miles: A. E14712.

364. Fragmento. XXX h. 18'00 × 9'1 mm. 0’5 g. BC-. Miles: ¿?. E14713. 


\section{2. Dirhames extrapeninsulares}

\subsubsection{Dirhames idrīsíes}

365. 226-7 h. Al-Bașra. 21'50 mm. 2'0 g. Eustache: similar a 4. E14715.

366. 22 ¿ 4 ? h. Al-'Aliyya. $20^{\prime} 15 \mathrm{~mm}$. 2'1 g. Eustache: $170 \mathrm{a}$ o similar. E14716.

367.231 (ld) h. Al-'Āliya. 22’85 mm. 1’7 g. Eustache, pp. 204 y ss. E14372.

\subsubsection{Dirham 'abbāsí}

368. 239 h. Miṣr. 25’05 mm. 2’1 g. Lavoix: 952. E14717. 

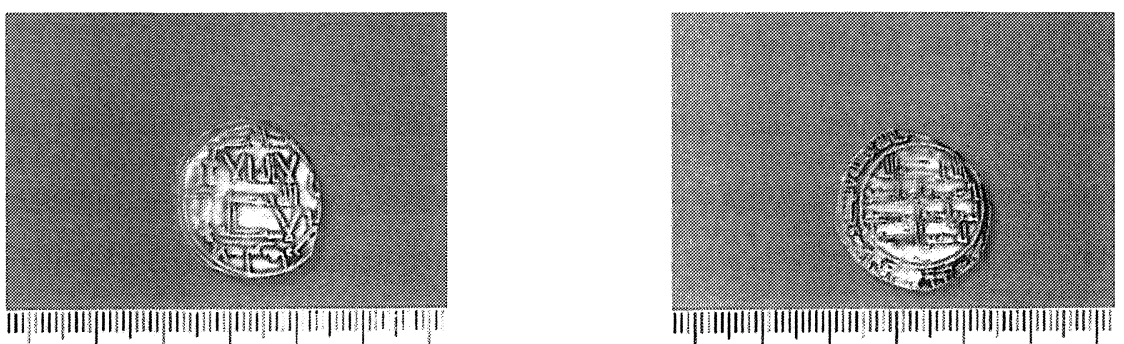

FIG. 1.-Dirham acuñado por ${ }^{\mathrm{c}} \mathrm{Abd}$ al-Rahmān I en 150 h./770-1 d.C. (N. 3 del catálogo)

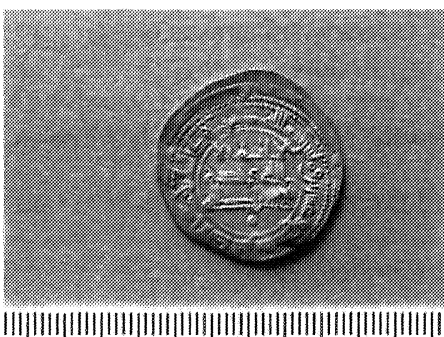

|||||||||||||||||||||||||||||||||||||||||||||||||||||||||| $\mid$

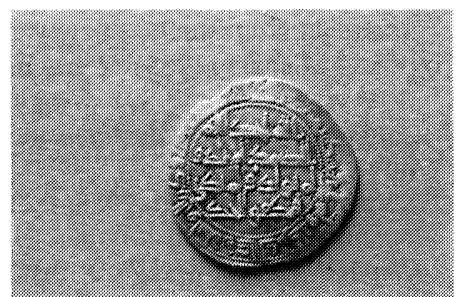

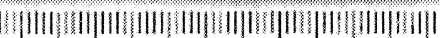

FIG. 2.-Dirham acuñado por ${ }^{c} \mathrm{Abd}$ al-Rahmmān II en 229 h./843-4 d.C.

(N. ${ }^{\circ} 123$ del catálogo)

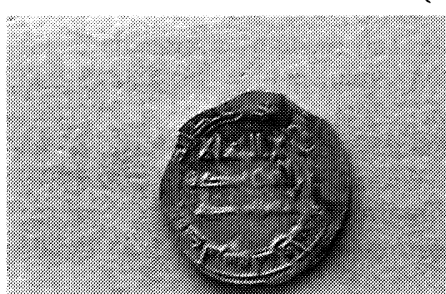

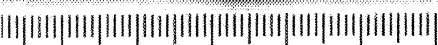

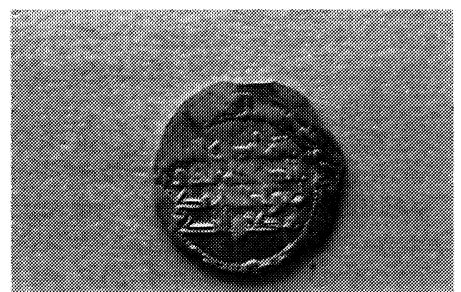

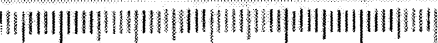

FIG. 3.-Dirham acuñado por Muhammad I en 242 h./856-7 d.C.

(N. 347 del catálogo)

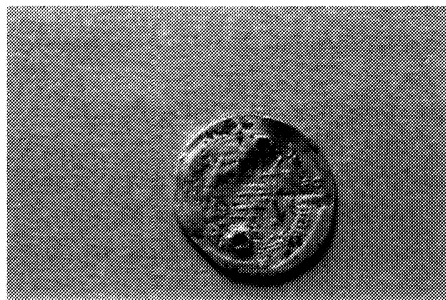

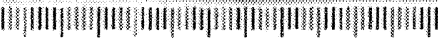

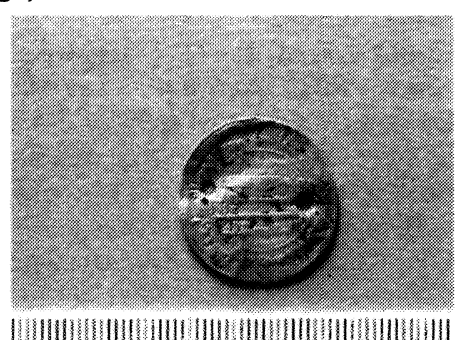

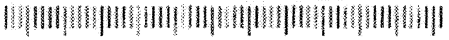

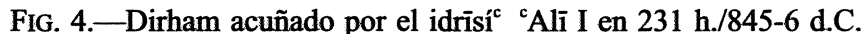

(N. ${ }^{\circ} 367$ del catálogo) 


\section{Referencias bibliográficas}

Álvarez DE Morales, Camilo (2000): «De la conquista musulmana a la abolición del califato omeya (siglos VIII-XI)», en Peinado Santaella, Rafael (ed.): Historia del Reino de Granada I: De los orígenes a la época mudéjar (hasta 1502), Granada: Universidad-El Legado Andalusí, 113-53.

ARIÉ, Rachel (1984): España musulmana (siglos VIII-XV), traducción de Berta Juliá, Barcelona: Labor.

BATES, Michael L. (1982): Islamic Coins, Nueva York: The American Numismatic Society.

BATES, Michael L. (1996): «The ${ }^{c}$ Abbasid coinage system, 833-946», comunicación presentada al Annual Meeting of The Middle East Studies Association, Nueva York: American Numismatic Society (Versión electrónica en www.amnumsoc.org.)

BROOME, Michael (1985): A Handbook of Islamic Coins, Londres: Seaby.

CANO ÁvILA, Pedro (1989): «Algunos dirhemes hallados cerca de Alcaudete (Jaén)», VII Congreso Nacional de Numismática: Memoria, Madrid: Museo Casa de la Moneda, 489-503.

CANTO García, Alberto (1988a): «El período omeya. El Emirato. La aparición de la tipología califal. 'Abd al-Rahmān III: sus sucesores», I Jarique de Estudios Numismáticos Hispano-árabes, Zaragoza: Institución Fernando el Católico, 29-41.

CANTO GARCIA, Alberto (1988b): «Tesoro de moneda emiral, del siglo II de la hégira, conservado en el MAN», I Jarique de Estudios Numismáticos Hispano-árabes, Zaragoza: Institución Fernando el Católico, 147-62.

CANTO, Alberto (1993): «Sobre un pequeño hallazgo de moneda emiral en Martos (Jaén)», Antiquitas (Ayuntamiento de Priego de Córdoba) 4, 63-6.

CANTO GARCÍA, Alberto (1999): «La moneda andalusí: ¿un modelo de moneda distinto?», Gaceta Numismática (Barcelona: Asociación Numismática Española) 133, 77-83.

[CANTO, Alberto y Tawfiq IBRAHIM] (1997): «Evolución de la moneda andalusí», Moneda andalusi en la Alhambra (Palacio de Carlos V-Granada, marzo-agosto 1997), Sevilla: Patronato de la Alhambra y Generalife-Scriptorium, 17-49.

CANTO, Alberto y Eduardo MARSAL (1988): «Hallazgo de moneda emiral de Iznájar (Granada)», Al-Oantara IX, 427-70.

CANTO GarCía, Alberto, Tawfíq ḤĀFIZ IBRĀHİM y Fátima MarTín EsCUdERo (2000): Monedas andalusies: Catálogo del Gabinete de Antigüedades, Madrid: Real Academia de la Historia.

CODERA Y ZAIDÍN, Francisco (1879): Tratado de numismática arábigo-española, Madrid: M. Murillo.

CODERA, Francisco (1913): «Monedas árabes orientales encontradas en Aragón», Boletín de la Real Academia de la Historia LXIII, 552-6.

CORRIENTE, Federico (1992): Árabe andalusi y lenguas romances, Madrid: Mapfre.

DAOUDI, Mohamed (1987): Monnaies médias: Essai, Rabat: Serar.

EUSTACHE, Daniel (1970-71): Corpus des dirhams idrisites et contemporains, Rabat: Banque du Maroc (Études sur la numismatique et l'histoire monétaire du Maroc).

FÓRNEAS, J.Ma (1980-81): «Joaquina Eguaras Ibáñez», Miscelánea de Estudios Árabes y Hebraicos XXIX-XXX/1, 213-6.

FROCHOSO SÁNCHEZ, Rafael (1996): Las monedas califales de ceca al-Ándalus y Madinat al-Zahrä' (316-403 H/928-1013 J.C.), Córdoba: Junta de Andalucía-Cajasur.

GARCIA-ARENAL, Mercedes y Eduardo MANZANO MORENO (1995): «Idrissisme et villes idrissides», Studia Islamica 82, 5-31. 
Gozalbes Cravioto, Carlos y José Antonio Ayala Ruiz (1995-96): «Un tesorillo de monedas de Emirato independiente hallado en el Cerro de la Fuensanta (Antequera-Casabermeja-Colmenar, Málaga)», Mainake (Diputación Provincial de Málaga) XVII-XVIII, 235-42.

GraBAR, Oleg (1973): The Formation of Islamic Art, Yale University Press. (La formación del arte islámico, traducción de Pilar Salsó, Madrid: Cátedra, 1979)

HASSAR-BENSLIMANE, Joudia (1995): «Las relaciones entre el arte meriní y nașrí», en Bermúdez López, Jesús (coord.): Arte islámico en Granada: propuesta para un Museo de la Alhambra, [Granada:] Junta de Andalucía-Comares, 173-9.

JiMÉNEZ MATA, M. Carmen (1990): La Granada islámica: Contribución a su estudio geográfico-politico-administrativo a través de la toponimia, Universidad de Granada.

LAVOIX, Henri (1887): Catalogue des monnaies musulmanes de la Bibliothéque Nationale, París: Bibliothèque Nationale.

LÉVI-PROVENÇAL, É. (1950): España musulmana hasta la caída del Califato de Córdoba (711-1031 de J.C.), traducción de Emilio García Gómez, Madrid: Espasa-Calpe (Historia de España dirigida por Ramón Menéndez Pidal).

LÉVI-ProvenÇAL, É. (1953): La civilización árabe en España, traducción de Isidro de las Cagigas, Madrid: Espasa-Calpe (Austral).

LÉVI-PROVENÇAL, É. y Emilio GARCÍA GÓMEZ (1948): Sevilla a comienzos del siglo XII: El tratado de Ibn ${ }^{c} A b d \bar{n}$, Madrid: Moneda y Crédito.

MARINHO, José Rodrigues (1983): «Uma prática singular em moedas do Emirado do Ândalus», O Arqueólogo Português IV, 1, 347-74.

Medina GómeZ, Antonio (1992): Monedas hispano-musulmanas: Manual de lectura y clasificación, Toledo: Diputación Provincial (Instituto de Investigaciones y Estudios Toledanos).

Mendoza Eguaras, Ángela (1976): «Tesorillo de monedas musulmanas de Píñar (Granada)», Cuadernos de la Alhambra 12, 267-77.

[MENDOZA EgUARAs, Ángela] (1983): «Tesoro de monedas de plata musulmanas de Domingo Pérez (Granada)», en Mendoza Eguaras, Ángela y Francisco González de la Oliva (coords.): Bellas Artes 83, Granada: Ministerio de Cultura-Museo Arqueológico-Museo de Bellas Artes, p. 67.

Miles, George E. (1950): The Coinage of the Umayyads of Spain, Nueva York: The American Numismatic Society.

PÉREZ-SINDREU, Francisco de Paula (1990): «Tesorillo de monedas emiral y califal encontrado en Carmona (Sevilla)», II Jarique de Numismática Hispano-arab, Mollerusa: Institut d'Estudis Ilerdencs, 181-4.

PRIETO VIVES, A[ntonio] (1915): «La reforma numismática de los almohades: ensayo sobre la numismática de los Estados hispano-africanos», Miscelánea de Estudios y Textos Árabes, Madrid: Centro de Estudios Históricos, 11-114.

PRIETO VIVES, Antonio (1926): Los Reyes de Taifas: Estudio histórico-numismático de los musulmanes españoles en el siglo $v$ de la hégira (XI de J.C.), Madrid: Junta para la Ampliación de Estudios e Investigaciones Científicas (Centro de Estudios Históricos).

SÁENZ-DíEZ, Juan Ignacio (1984): Las acuñaciones del Califato de Córdoba en el Norte de África, Madrid: Vico-Segarra.

VEGA MARTín, Miguel y Salvador PeÑa MARTín (2001): «La mejora epigráfica del 229 h.: sentido y forma en las leyendas del dirham emiral», IV Jarique de Numismática Andalusí, Jaén, 19-21 de octubre de 2000, Universidad de Jaén, 121-134.

Vega MARTín, Miguel, Salvador PEÑa MARTín y Manuel C. Feria GaRcía (en prensa): El mensaje de las monedas almohades: Numismática, traducción y pensamiento islá- 
mico, Cuenca: Universidad de Castilla-La Mancha (Escuela de Traductores de Toledo).

WALKER, John (1956): A Catalogue of the Arab-Byzantine and Post-reform Umaiyad Coins, Londres: British Museum.

WASSERSTEIN, David: «Islamic coins and their catalogues: a problem case», Al-Qantara $\mathrm{XX} / 1,221-32$.

\title{
RESUMEN
}

La descripción detallada de un hallazgo considerable de dirhames y fragmentos de dirhames realizado en las proximidades de Iznalloz (Granada) nos lleva a plantear una serie de cuestiones acerca de la trascendencia del reinado de 'Abd al-Raḥmān II en la historia numismática de al-Ándalus, sobre todo, lo relativo a la posible existencia de más de una ceca emisora.

\begin{abstract}
A medium-size hoard of dirhams struck by the Andalusi Umayyad Emirate and found in Iznalloz (Granada, Spain) is described. Some details of the description could help to put some light on certain obscurities, such as 'Abd al-Rahmān II's role in the history of Andalusi numismatics and the unsolved problem of the exact reference of the term al-Andalus as a mint.
\end{abstract}

